\title{
El ascenso "pacífico" de China: la moral en la política exterior hacia América Latina
}

\author{
China's "peaceful" rise: moral in foreign \\ policy towards Latin America
}

\author{
Tonatiuh Fierro De Jesús*
}

\begin{abstract}
RESUMEN
El artículo analiza el uso recurrente de la retórica moral en la política exterior de China hacia América Latina en los gobiernos de Hu Jintao y Xi Jinping, con el fin de procurar y mantener un ambiente "pacífico", para lograr el plan de rejuvenecimiento nacional en 2049. Argumenta que frente a las hipótesis de la "amenaza china" hechas en Occidente, China ha recurrido a los valores morales para disuadir tales temores en sus relaciones políticas internacionales. Después de estudiar la vinculación entre la moral y la política exterior desde la problematización teórica, se examina cómo se integra y ejecuta la moralidad en la política exterior económica y en la política multilateral de China en la CELAC y la Iniciativa de la Franja y la Ruta. Concluye que existe un desfase y una tensión persistente entre el discurso moral del gobierno chino con el no reconocimiento y la responsabilidad de proteger los derechos de las comunidades locales y el medioambiente en los territorios latinoamericanos de Estados frágiles, donde tienen presencia sus proyectos económicos.
\end{abstract}

Palabras clave: China - América Latina - Xi Jinping - Moral Política Exterior.

Profesor e investigador visitante del Instituto Internacional de Estudios Políticos Avanzados, Ignacio Manuel Altamirano (IIEPA-IMA) de la Universidad Autónoma de Guerrero. Doctorando en Ciencias Políticas y Sociales por la Universidad Nacional Autónoma de México (UnAm). Maestro en Estudios de Asia y África, con especialidad en China, por El Colegio de México, y licenciado en Relaciones Internacionales por la UNAM. Correo electrónico: fierrotonatiuh@ gmail.com. ORCID: 0000-0002-2689-2321.

Recibido: 14 de mayo de 2019. Modificado: 1 de marzo de 2020. Aceptado: 11 de junio de 2020. 


\begin{abstract}
The article analyzes the recurring use of moral rhetoric in China's foreign policy toward Latin America of the Hu Jintao's and Xi Jinping's governments with the aim to ensure a "peaceful" environment to achieve the goal of national rejuvenation by 2049. This investigation argues that China draws on moral values to deter the fears that China's global rise causes in the West. Firstly examining the relation between moral and foreign policy through of the theoretical problematization, and secondly, how moral in foreign policy will be implemented in China's economic foreign policy and multilateral policy, with particular emphasis in CELAC and Belt and Road Initiative. The work concludes that there is a gap and a persistent tension between the China's official moral discourse with the responsibility to protect the rights of local communities and the non-recognition of environmental problems in Latin American territories of fragile states where their economic projects are running actively.
\end{abstract}

Keywords: China - Latin America - Xi Jinping - Moral - Foreign Policy.

\title{
INTRODUCCIÓN
}

El propósito de este artículo es contribuir al análisis de la moral como instrumento diplomático de la política exterior de China hacia América Latina y el Caribe (ALYC) en las primeras dos décadas del siglo xxi, en el proceso de transición de convertirse en una potencia global. Es cierto que hay un debate sobre el significado de los conceptos de ética y moral. Sin embargo, este trabajo no cubrirá dicha discusión y únicamente se enfocará en explicar el nexo de la moral y la política exterior, reflejado en sus relaciones con aLYc. Es decir, en la comprensión de la totalidad de su política exterior en su capacidad de articular los intereses y objetivos nacionales influenciados por los valores morales.

En el subcampo del Análisis de Política Exterior (APE) se ha intentado explicar y analizar, desde una forma interdisciplinaria, la integración de la ética y la moral en la formulación y 
ejecución de la política exterior ${ }^{1}$, por ejemplo, en los artículos de Chris Brown "Ethics, Interests and Foreign Policy"; Leslie Gelb y Justine A. Rosenthal, "The Rise of Ethics in Foreign Policy: Reaching a Values Consensus"; Joshua D. Kertzer, Kathleen E. Powers, Brian C. Rathbun y Ravi Iyer, "Moral Support: How Moral Values Shape Foreign Policy Attitudes"; Dan Bulley, "Foreign Policy as Ethics: Toward a Re-Evaluation of Values”, y más recientemente, Joseph S. Nye Jr., "What Is a Moral Foreign Policy?"

También ha habido un esfuerzo académico para entender el ascenso global de China sin recurrir a generalizaciones y argumentos reduccionistas que encasillan a la política exterior de los países poderosos con una ideología política liberal. Entre estas propuestas analíticas encontramos a Jamie Gaskarth, "Rising Powers, Responsibility, and International Society"; John J. Mearsheimer, "Can China Rise Peacefully?”; Zheng Bijian — precursor de

1 Aunque etimológicamente moral y ética tienen el mismo significado, la primera del latín mos y la segunda del griego ethos, para fines prácticos, tomamos los conceptos de la Real Academia Española. Moral: "Conjunto de costumbres y normas que se consideran buenas para dirigir o juzgar el comportamiento de las personas en una comunidad". Ética: "Conjunto de costumbres y normas que dirigen o valoran el comportamiento humano en una comunidad". La moral tiene una base social que la distingue de una sociedad a otra y rige la vida de sus habitantes, mientras que la ética tiene un carácter individual que nace de la conciencia misma de la persona. esta teoría—, "Chinese Rise Peacefully", y Yan Xuetong en su artículo "From Keeping a Low Profile to Striving for Achievement" o en sus libros Ancient Chinese Thought, Modern Chinese Power y, el más nuevo, titulado Leadership and the Rise of Great Powers.

Estos últimos dos autores de origen chino, gracias a su cercanía con la élite política del Partido Comunista de China (PCC), han sido los encargados, entre otros, de construir y elaborar el lenguaje diplomático y, hasta cierto punto, influir en la imagen de China en el exterior que se difunde por medio de los círculos académicos y políticos. Con la finalidad de entender la actuación de China en ALYc, se utilizará la teoría del Realismo Moral (RM) de Yan Xuetong, ya que sus postulados aportan consideraciones acerca de la función de la moral en la formulación de la política exterior, las cuales se plasman en las siguientes interrogantes: ¿por qué es importante el estudio de la moral en la política exterior? ¿Cuál ha sido el cambio más decisivo del uso de los valores morales que promueve China en el exterior desde la llegada de Xi Jinping? ¿La moral en la política exterior de China norma su actuación externa? ¿Hay congruencia en las intenciones, medios y consecuencias de la política exterior moral de China en ALYC?

Con base en lo anterior, se proponen cinco argumentos centrales que interactúan entre sí, teniendo como punto de partida el eje moral: 
1. Desde principios del siglo xxI, las hipótesis sobre "la amenaza china” a la seguridad internacional determinaron que en la retórica diplomática de Beijing se integrará, de forma activa, un nuevo lenguaje "pacifista" a la diplomacia china para convencer a los Estados que ella no representa un peligro, con el fin de preservar, proteger y promocionar sus intereses y objetivos nacionales. Estrategia pacifista que ha trascendido los cambios de administración.

2. Al mismo tiempo que China pareciera tener la voluntad de comportarse como un líder moral, de acuerdo con el enfoque del RM de Yan Xuetong, la construcción de la agenda de la política exterior activa de China hacia ALYC privilegia el poder económico — de visión capitalista - sobre el poder militar y el poder cultural, en detrimento de los derechos sociales y ambientales. De este modo, la presencia e influencia de China en ALYc ha ido en aumento, logrando éxitos diplomáticos importantes al ampliar su acceso a nuevos mercados y materias primas, y al aislar continuamente a Taiwán de la región.

3. Dado que China no utiliza su poder militar y trata de no interferir en los asuntos internos de los Estados latinoamericanos, todavía es moralmente cuestionable su silencio ante hechos que contribuirían a coadyuvar a la seguridad regional, como el apoyo a la administración de Nicolás Maduro en Venezuela o su no postura definida frente al golpe de Estado del gobierno de Evo Morales. Panorama que traería serias limitaciones para el logro de sus objetivos en ALYc, a la vez que aumentaría su desprestigio ante la opinión pública regional.

4. Aún cuando las políticas proteccionistas del gobierno de Trump han aumentado, ALYC sigue siendo la zona de influencia geopolítica de la superpotencia. Por ello, China no ha tratado de desafiar militarmente a EE.UU. El uso de la política exterior activa de China es un medio para el logro de sus objetivos e intereses nacionales, empero, la asimetría de poder ha hecho que ahora algunos países de ALYC queden sujetos a una doble dependencia y a una doble agenda de política exterior, sin que exista una estrategia por parte de dichos Estados para encontrar equilibrios o una independencia relativa respecto de China y EE.UU.

5. China continuará con el apoyo hacia los países de ALYC para que tengan voz en los asuntos multilaterales, siempre y cuando esas posiciones estén conciliadas con sus intereses y objetivos internos.

El trabajo está dividido en tres secciones. En la primera parte, se examina el vínculo entre la moral y la política exterior a partir de la revisión de la literatura del APE. Asimismo, se hace una breve descripción del RM y 
su vínculo con la política exterior de China; se incluye la retórica "pacifista" de las dos últimas administraciones de China en la insistencia de convertirse en una potencia global con prestigio, legitimidad e influencia. En la segunda parte, se observa que las relaciones de China con ALYC privilegian la economía por sobre otros rubros de la política exterior. Esta sección señala que existen tensiones e inconsistencias del discurso oficial chino. La contradicción radica en que la política exterior moral de China no compagina con la promoción de los derechos sociales de las comunidades locales donde tienen presencia sus proyectos económicos. Por lo que existe un consistente dilema entre el autoritarismo de su régimen y la manera en que establece relaciones económicas con países democráticos, pero con gobiernos frágiles. En la última parte se aborda la inserción asertiva de China en la región por medio de la diplomacia multilateral.

\section{Objetivos e intereses de la política eXterior de China en AmÉRICA LATINA}

La trayectoria de la política exterior de China hacia ALYC en el siglo XXI es, a la vez, la historia de un proceso de inserción de Beijing al sistema económico y político internacional, además de un reforzamiento político-institucional del gobierno chino y, principalmente, de legitimidad para el PCC de los logros alcanzados por la política interna y externa.

Desde 2012, con Xi Jinping ${ }^{2}$ en el poder ha habido un cambio más ambicioso y sofisticado de la política exterior de China, pero continuando con los ideales de sus predecesores, quie-

2 El 25 de octubre de 2017, durante el xix Congreso del PCC, Xi Jinping fue reelegido como secretario general. El 17 de marzo de 2018, la Asamblea Nacional Popular de China aprobó por unanimidad a Xi Jinping como jefe de Estado chino para un segundo periodo (2018-2023). nes enarbolan la relevancia de que China ocupe un espacio primordial en la toma de decisiones de la política internacional. Con cambios en la estrategia diplomática, la República Popular China (RPC) recurre a la política exterior como continuación de su política interna para alcanzar los objetivos nacionales y promover el interés nacional. En esta simbiosis de objetivos e intereses vislumbrados a largo plazo, ¿cuál es el lugar que ocupa a ALYC en esos intereses y objetivos? Algunos de ellos son:

1. Convertir a China en 2049 (centenario de la RPC) en un Estado socialista moderno: "próspero, fuerte, democrático, avanzado culturalmente y armonioso". Esto es, a su vez, un objetivo interméstico que busca la consolidación del "Sueño Chino". 
2. Conservar el régimen político monopolizado por el partido de Estado bajo la dirección de Xi Jinping, para acrecentar el prestigio y legitimidad del Pcc en el país y en el extranjero, como partido de Estado.

3. Contribuir a la reconfiguración del régimen internacional y a un nuevo orden global centrado en China, a fin del incremento de poder e influencia a nivel global.

4. Mantener y consolidar la integridad territorial, expresada en su política de aislamiento y presión a Taiwán.

5. Lograr las metas de desarrollo consistentes en la adquisición y afianzamiento de sus proveedores de materias primas y recursos naturales estratégicos para sus proyectos económicos.

6. Promover el comercio y expandir sus proyectos económicos mediante el posicionamiento de un modelo comercial tecnológico sofisticado, como la venta de software y celulares inteligentes, además de buscar espacios para la inversión en infraestructura y socios para otorgar préstamos financieros estratégicos.

7. Ser reconocida como una economía de mercado.

8. Posicionar sus sectores clave: energía y recursos, obras de infraestructura, agricultura, manufactura, innovación científica y técnica, y tecnologías de la información, sin que la cooperación militar prevalezca.
En un mundo cada vez más complejo, incierto y cambiante, la política exterior tanto de China como la de los países de ALyc enfrenta serios desafíos frente al ascenso de las ideologías políticas proteccionistas, conservadoras y autoritarias, donde el uso de las fuerzas armadas para irrumpir en el orden constitucional no puede descartarse. Para ilustrar, los hechos más actuales son el golpe de Estado al gobierno de Evo Morales en Bolivia y el uso de los militares en El Salvador, por mandato de Nayib Bukele, para reprimir al parlamento. Ellos constituyen símbolos de la debilidad de las instituciones internas de los Estados latinoamericanos debido a los problemas de corrupción, impunidad y desigualdad. Ante el menosprecio del globalismo y el multilateralismo de algunos jefes de Estado, como el estadounidense Donald Trump, el gobierno de Xi Jinping ha propuesto que sus relaciones se afiancen en los principios de "beneficio mutuo", "ganar-ganar" y de "igualdad" a nivel bilateral y multilateral. No obstante, ¿qué tan cierto y congruente es el discurso de China con los hechos? Esto se tratará de responder más adelante.

Como respuesta a las pretensiones de China, algunos gobiernos latinoamericanos de orientación progresista no han renunciado a su facultad soberana de profundizar sus relaciones políticas y de cooperación con China, manteniendo distancia respecto de las presiones de Estados Unidos (EE.UU.). En contraste, los gobiernos 
identificados como conservadores, e incluso algunos de corte progresista, no han respondido positivamente - al menos en el discurso político- al ascenso de China debido a que sus políticas exteriores están determinadas en función del peso político-ideológico estadounidense, que limita y contiene el avance chino. Tal es el caso del Brasil de Jair Bolsonaro y del México de Andrés Manuel López Obrador (AMLO).

Tampoco se puede ignorar que el no interés del gobierno de Trump por ALYC, probablemente solo sea coyuntural. Por razones geopolíticas, difícilmente la superpotencia podría abandonar su zona de influencia como una esfera de seguridad nacional. En caso de un enfrentamiento hegemónico entre China y EE.UU., los intereses económicos de Beijing en ALYC son tan necesarios para su desarrollo que difícilmente podría dejarlos en el abandono.
Por un lado, por más que el pragmatismo de las políticas exteriores de China y aLYC ha funcionado para profundizar sus relaciones económicas, la diversidad de intereses, el disenso y las contradicciones regionales para articular una estrategia política y responder conjuntamente a la presencia de China, no se ha logrado. Por otro lado, el legado de la historia intervencionista y golpista de los grandes poderes en la región han marcado el actuar de los Estados latinoamericanos: buscan una independencia relativa tanto de EE.UU. como de China para evitar choques con las principales potencias, con el fin de salvaguardar su soberanía. De modo que es importante estudiar el contexto de la toma de decisiones de política exterior que realiza el gobierno chino, teniendo como punto de partida las probabilidades y limitaciones de espacios de acción en ALYc.

\section{LA MORAL EN EL ANÁLISIS DE POLÍTICA EXTERIOR}

\section{Teoría: Realismo Moral}

El objetivo de este apartado es subrayar los argumentos principales de Yan Xuetong en torno al RM y cómo estos delinean el análisis de la política exterior de China. Aunque los temas y debates acerca de la moral en la disciplina de las Relaciones Internacionales son de larga data, estos han ocupado un lugar secundario. El asunto que se ha posicionado en la palestra tiene que ver con el ascenso de China como una potencia global reemergente y si existe la posibilidad de que la nación asiática se comporte de una manera distinta a los otros poderes tradicionales, que se caracterizaron por una expansión imperial bélica y capitalista.

En efecto, el incremento de su poder ha afectado el orden de la comunidad internacional, lo que hace que su 
ascenso global incluya cuestionamientos morales sobre su responsabilidad global. En el APE, los conceptos de la moral y la ética se han tomado como indistintos. A pesar de sus diferencias, los teóricos citados se han orientado a enfatizar los compromisos y responsabilidades morales que adquieren los Estados en el exterior. Por el momento, describiremos brevemente la relación entre la moral y la política exterior. La moral - para fines de este trabajo - es entendida como el conjunto de normas, principios y valores que construyen y definen a una sociedad.

Ahora bien, ¿cuál es el valor de la moral en la política exterior? Joseph Nye argumenta que "determinar una política exterior moral no es una cuestión de intenciones versus consecuencias, sino que debe incluir a ambos, así como a los medios utilizados" (Nye, 2019). Yuen Foong Khong, por su parte, admite que las analogías históricas sirven para evaluar la política sobre la base de los resultados pronosticados, evaluar la calidad moral y, en cierto modo, prever posibles escenarios riesgosos (Yuen, 1992).

En este sentido, adquiere relevancia el análisis de la moral en la política exterior en el contexto de la reemergencia de China y la posible antesala de la debacle hegemónica de Estados Unidos. En este proceso histórico específico, "los líderes con buenas intenciones, pero con poca inteligencia contextual y pruebas de realidad imprudentes, a veces producen malas consecuencias y conducen al fracaso ético". De esta forma, “dada la complejidad de la política exterior, la prudencia es más que una virtud instrumental. Un buen razonamiento moral sobre las consecuencias también debe considerar mantener un orden institucional que fomente los intereses morales". Incluso, las "no acciones" se pueden considerar como consecuencias éticas (Nye, 2019). En esta línea, para Dan Bulley, las políticas exteriores se expresan a través de normas e ideas. Por ello, se debe repensar la política exterior como ética para dejar abierta la posibilidad de una "mejor" relación con el exterior, incluso cuando las preguntas sobre el "deber" no son explícitas en su práctica (Bulley, 2014: 21). Como expresan Joshua D. Kertzer, Kathleen E. Powers, Brian C. Rathbun y Ravi Iyer (2014: 2), "los valores morales a menudo construyen percepciones de lo que es el interés nacional".

A partir de la perspectiva del Realismo Político (RP), en un contexto internacional anárquico, en el cual los Estados actúan con base en su interés nacional definido en términos de poder, Chris Brown crítica que los Estados tienen deberes más amplios que los intereses de sus pueblos — siempre legítimos-, "estos dos deberes [nacional y externo] implican obligaciones morales y es un error pensar que el primero solo debe estar basado en intereses nacionales, mientras que el segundo constituye la dimensión ética de la política exterior" (Brown, 2001: 26). Para Brown, la política interna y la política exterior no deben mantenerse 
distantes y no son de naturaleza distinta; los principios y valores morales norman la acción de los Estados.

De acuerdo con Michael Nicholson, la importancia de la moral estuvo presente en el "primer gran debate" en las Relaciones Internacionales entre realistas y utopistas -idealistas liberales-, a pesar de que "solo unos pocos miles de personas se dieron cuenta" (Nicholson, 1998). Aunque en la teoría del RP de Hans Morgenthau se enfoca en la lucha por el poder como una categoría universal de los Estados; la ideología y la ética son justificaciones falsas o racionalizadas, el objetivo de todo Estado es mantener, lograr o maximizar el poder, en el cual los "principios morales universales no pueden aplicarse a las acciones de los Estados en su formulación universal abstracta, pero [...] debe ser filtrada a través de las circunstancias concretas de tiempo y lugar" (Morgenthau,1963: 10). Por tanto, la moralidad pondría en dificultad el logro de los objetivos de los Estados, al estar su actuación normada. No obstante, el autor tampoco la descarta en momentos específicos.

Así pues, para Morgenthau "la diplomacia es el cerebro del poder nacional, como la moral es su alma”. De este modo, la moral nacional es "el decreto de la determinación con la que una nación apoya las políticas exteriores de su gobierno en paz o guerra". "La diplomacia de alta calidad traerá los fines y los medios de política exterior en armonía con los recursos disponibles del poder nacional" (Morgenthau, 1948:
147 y 153). Edward Carr, por su parte, afirma que los políticos "encubren sus intereses en un disfraz de principios morales" (Carr, 1939: 117).

La escuela del RP es una de las más fuertes en el estudio de las Relaciones Internacionales, principalmente en la academia anglosajona. Sin embargo, sus planteamientos han tenido importantes críticas desde la década de 1960 y se han reforzado en la primera década del siglo xxI, debido al declive hegemónico de Estados Unidos y el impacto negativo de su prestigio desde el inicio de la "guerra contra el terrorismo" y acentuada con el arribo a la Presidencia de Donald Trump, en 2017.

Entre las críticas más destacadas al RP se encuentra la de Yan Xuetong (entre otros críticos clásicos se encuentran Robert Keohane y Stanley Hoffmann). Si bien Yan retoma el concepto del RP, el autor sugiere que la moral no puede ser marginal en los estudios de las Relaciones Internacionales, especialmente de China, como lo hicieron Morgenthau y Carr, al poner toda su atención en el análisis del poder político-militar y no considerar otras variantes que afectan al poder en su totalidad, como la economía, la cultura o la moral.

$Y$ es que el debate actual es que los tomadores de decisiones en la política exterior deben tomar en cuenta las consecuencias morales de sus actos. Según Leslie H. Gelb y Justine A. Rosenthal (2003: 6), la intervención humanitaria es "quizás el ejemplo más dramático del nuevo poder de 
la moralidad en los asuntos internacionales" y en el cual el concepto de poder se amplía y complejiza en un mundo más peligroso, incierto y cambiante. En una sociedad anárquica, los poderes emergentes y reemergentes como China - explica Jamie Gaskarth-, debido a su experiencia colonial, "tienden a definir su responsabilidad en términos de contribución a los bienes públicos mundiales, en lugar de a través del uso de la fuerza" (Gaskarth, 2017: 11).
Finalmente, como James Rosenau lo hace notar, la política en todos sus niveles considera "la gama completa de procesos individuales y colectivos por los cuales las personas buscan dar sentido y esperanza a sus vidas" (Rosenau, 1987: 3). Por ahora, la moral en la política exterior daría un significado mayor del "deber ser" de los Estados a nivel interno y externo. Hoy por hoy, "la moral está en el corazón del pensamiento sistemático sobre las relaciones internacionales" (D. Kertzer et al., 2014: 2), cuestionada o no.

\section{El Realismo Moral}

El Realismo Moral es una teoría que une los conceptos del Realismo Político en las Relaciones Internacionales con conceptos tradicionales relacionados a la filosofía china de la antigüedad, como Xunzi (312-230 a.C.), que tiene como base las enseñanzas de Confucio (551-479 a.C.) y señala que la naturaleza del hombre es mala. No obstante, es mediante la conducta moral y el estudio, que el ser humano puede regenerarse o seguir el camino apropiadamente.

Es interesante el contexto en el cual Yan retoma a Xunzi porque fue este último autor quien vivió en un tiempo de guerra y caos. Así pues, la teoría de Yan Xuetong enriquece el análisis de la política exterior de China al incorporar los conceptos y valores tradicionales, principalmente, confucianos: la equidad (公平) y la justicia (正
戈), entre otros. En Ancient Chinese Thought, Modern Chinese Power, Yan hace una analogía de los períodos de Primavera y Otoño (770-476 a.C.) y de los Reinos Combatientes (475-221 a.C.) para explicar el escenario actual de las relaciones internacionales, también caracterizado por el desorden.

En la actualidad, existe un término muy usado en la élite política del PCC, es wangdao (王道) o "autoridad humana”. Yong Chen, especialista en confucianismo, al estudiar a Jiang Qing, pionero de los movimientos confucianos contemporáneos, revela que "el sistema político ideal para China no es la democracia,sino más bien "la política regia" (wangdao zhengzhi 王道 政 治)", ahí podemos encontrar la esencia del confucianismo. El poder político tiene tres fuentes de legitimidad: las sagradas, la continuidad histórica y el 
apoyo de la gente al poder político y su partición política (Chen, 2015: 68). En cierto punto, el término de wangdao explica la naturaleza de la cultura política en China, y en la transición de convertirse en una potencia global, quiere seguir manteniendo ese grado de legitimidad. En relación con esto, Yan Xuetong considera que "la palabra denota a China como un hegemón benevolente e iluminado, que es poderoso y legítimo porque satisface las necesidades económicas y de seguridad de otros países, siempre y cuando, a cambio de la aceptación del liderazgo chino" (Yan, 2019: 133). Un término que es muy parecido al concepto de Tianxia ${ }^{3}$.

Para el autor, el poder se centraliza en el Estado como actor principal y se expresa según la ecuación $\mathrm{CP}=(\mathrm{M}+\mathrm{E}+\mathrm{C})$ x $\mathrm{P}$; "CP" significa el poder nacional total; " $\mathrm{M}$ " es el poder militar; "E" el poder económico; "C" el poder cultural,y " $\mathrm{P}$ ” el poder político. Fórmula que es una mezcla de poder duro y suave, que constituyen los recursos de poder para que el poder político opere (Yan, 2011: 102). El uso de los recursos — calidad y cantidad-con

3 Tianxia 天下 o “Todo bajo el Cielo" fue la visión del mundo para los chinos durante la dinastía Han (206 a.C-220 d.C.) hasta la caída de la dinastía Qing (1644-1912 d.C.) en el siglo xix. El Tianxia significaba que el emperador era el "Hijo del Cielo", el mediador entre el universo y todos los seres humanos, lo cual legitimaba su poder. China, como Zhongguo 中国 o "el Reino del Centro", dictaminaba las normas universales de la civilización. los que cuenta el Estado multiplicarán o no su margen de maniobra política interna y externa. Para Yan, los recursos determinan y explican la acción política interna de China, pero también ayudan a definir sus objetivos de política exterior actual. Sin embargo, esta categoría no es universal, es específica de la nación asiática para explicar sus intereses en términos de poder, pero con nuevas variantes constitutivas del poder chino en la búsqueda de convertirse en una potencia global.

Yan Xuetong recurre al RP para destacar los conceptos de "poder" como meta de la política exterior y "fuerza" como un instrumento eficaz para incrementar la influencia y presencia global.En en su teoría del RM, el autor explica los beneficios de ser un poder ascendente con un liderazgo político basado en "la autoridad humana" para establecer un entorno global que le sea favorable, claramente jerárquico. Aunque Yan no menciona la palabra prestigio, señala que la credibilidad internacional "es un requisito previo para que un poder en ascenso establezca" un nuevo polo de poder líder y "atraiga más aliados" que el actual poder hegemónico global (Yan, 2014). De este modo, el poder moral tiene un impacto sustancial en la formulación de la política exterior del poder ascendente.

La teoría del RM tiene tres argumentos centrales. En primer lugar, "la moral internacional desempeña un papel importante en la legitimación de las políticas y en el aumento del 
poder nacional". Segundo: "la política exterior moral es favorable al interés estratégico de un poder creciente". Tercero: "la política nacionalista de un Estado con autoridad humana puede ser humanitaria cuando su política esté guiada por las preocupaciones del liderazgo global", poniendo de ejemplo el concepto de Tianxia (Yan, 2014). A diferencia del RM, el RP considera que la función de la moral internacional es la protección de la vida humana; la política exterior guiada por la moral internacional sacrifica los intereses nacionales, y el nacionalismo, generalmente, no tiene un fin humanitario.

También Yan ha señalado la contradicción estructural entre un poder ascendente y el poder establecido. Él sostiene que "el poder en ascenso nunca tendrá un entorno favorable a menos que pueda moldear de manera iniciática [propositiva] y moral el entorno internacional". El poder ascendente debe "asumir la responsabilidad de seguridad para un mejor entorno internacional, de lo contrario, el dilema del aumento de poder deteriorará automáticamente sus relaciones con otros países". Por supuesto, la base de las relaciones estratégicas del poder ascendente es la cooperación y las alianzas en materia de seguridad. De esta forma, los poderes menores dependerán más del nuevo poder que emerge para obtener de ellos "más apoyo estratégico" (Yan, 2014).

En su teoría, Yan Xuetong toma en cuenta la teoría de guerra hegemónica de Robert Gilpin. El conflicto, que pone en juego a los liderazgos, traería cambios fundamentales en el sistema internacional, caracterizado por la anarquía. En este sentido, como consecuencia de la guerra ideológica, el Estado vencedor moldeará el sistema a su imagen con base en sus propios intereses nacionales y valores. $\mathrm{El}$ impacto será de largo alcance, el cual traerá transformaciones sociales, económicas y políticas (Gilpin, 1988). En esencia, las dos teorías comparten el impacto de la transición hegemónica, centrada en la variable militar y la importancia de la guerra, pero con la diferencia de una nueva variable: la moral. Este nuevo elemento es el núcleo de la teoría de Yan Xuetong. En su ecuación, el autor chino no ignora el elemento militar, económico y cultural. No obstante, privilegia la acción política como multiplicadora de los instrumentos del poder duro y suave, determinada por la moral. La tesis de Yan Xuetong pone en entredicho la premisa del paradigma realista tradicional de que la transición de un poder en ascenso a global, llámese China, se da en un contexto de conflicto o invasión armada o coerción económica. Asimismo, la lucha por el poder no únicamente se determina por los acontecimientos internacionales, sino también por las disputas internas. La cohesión interna es importante para la proyección del poder chino en el exterior.

En una guerra hegemónica, entiéndase China y EE.UU., "el perdedor será aquel al que la comunidad 
internacional considere inmoral [...] La moralidad es incluso más importante para que una potencia con estatus hegemónico mantenga su dominio que para que una potencia emergente se haga con el liderazgo, lo que significa que Estados Unidos depende más de la superioridad moral [...] que China" (Yan, 2013).La otra cara de la teoría de Yan es la crítica que le hace John J. Mearsheimer a la moralidad del ascenso de China. Según el punto de vista de este autor, no hay buenas razones históricas ni actuales para "pensar que China actuará de manera diferente en el futuro" (Mearsheimer, 2014).

Frente a esta lucha por el poder mundial, los Estados latinoamericanos han establecido una doble agenda de política exterior hacia EE.UU., principalmente en temas económicos, de política regional y lazos militares. Por otra parte, hacia China — donde la prioridad son los asuntos económico-comerciales - ALYC queda sujeta en una doble dependencia. Es así que la moralidad es el elemento determinante para que un poder ascienda y mantenga su dominio global, en el cual ALYC podría convertirse en el centro de la disputa por el poder mundial. En buena medida, lo dicho por Mearsheimer se verá plasmado en la actuación de las empresas chinas en ALYC y pondrá en contradicción a China al no asumir su responsabilidad global. En línea con Yan, China al depender de su moralidad, si no instaura nuevos mecanismos para cumplir con sus obligaciones extraterritoriales, sus relaciones con la región podrían deteriorarse.

Desde inicios del siglo xxI, es notorio el liderazgo activo de China en ALYC y su disposición para el diálogo y el consenso político en distintos espacios multilaterales, entre ellos destaca la Comunidad de Estados Latinoamericanos y Caribeños (CELAC), y proyectos definidos de largo plazo como la Iniciativa de la Franja y la Ruta (IFR). De este modo, mediante su política exterior, China actúa de forma racional para minimizar los riesgos y maximizar los beneficios, de manera de lograr sus objetivos nacionales y promover su interés nacional. Si bien su presencia no es disruptiva como otros poderes extra hemisféricos, en algunos Estados de la región ya se observan algunos componentes de conflicto, como veremos más adelante.

Aunque Yan Xuetong está más enfocado en que el poder ascendente se dedique a crear un ambiente propicio para el logro de sus objetivos e intereses, donde adquiera credibilidad debido a su comportamiento moral, omite analizar cuando los intereses y objetivos nacionales se contradicen con sus acciones externas, lo que dificulta a la teoría del RM explicar la totalidad de la política exterior de China, al ya tener un estatus mayor en las relaciones internacionales, comparado con el rol que tenía a principios del cambio de siglo. 
La retórica moral en la política exterior hacia América Latina

En el área diplomática, desde 2003 China ha recurrido a la doctrina del ascenso pacífico de Zheng Bijian y, poco tiempo después, a la terminología del desarrollo pacífico. Con ello, Beijing envía el mensaje al mundo de que no constituye una amenaza y que establecerá relaciones multilaterales y bilaterales de ganar-ganar, en vez de un juego de suma-cero. La política exterior de $\mathrm{Hu}$ Jintao giró hacia una actitud moderada y precavida. Por tanto, la construcción discursiva de China es una respuesta a las hipótesis que abundan en Occidente de la supuesta "amenaza china".

En este sentido, mediante la introducción del elemento pacifico, China envía la señal de que su ascenso hegemónico no es de expansión o de

4 Las hipótesis acerca de "la amenaza china" se utilizan para referirse a un grupo de académicos, políticos y medios de comunicación que analizan o ven el ascenso de China como un peligro militar y económico a otros países o al orden mundial existente, en un claro desafío hacia Estados Unidos. Entre algunos académicos, principalmente estadounidenses, que tratan sobre "la amenaza china" destacan: Ross H. Munro en su publicación Awakening Dragon: The Real Danger in Asia is from China (Policy Review, 1992), Samuel Huntington en su artículo The Clash of Civilizations (Foreign Affairs, 1993), Denny Roy en su trabajo Hegemon on the Horizon? China's Threat to East Asian Security (International Security, 1994) y Susan L. Shirk en su libro China: Fragile Superpower (Oxford University Press, 2007), entre otros. apropiación de territorios. En otras palabras, que ella no necesita de guerras para llegar a ser una potencia global. Es necesario mencionar que las teorías políticas de Karl Marx, Mao Zedong y el pensamiento político-moral de Confucio, rigen el Pensamiento de Xi Jinping sobre el Socialismo con Características Chinas para una Nueva Era, ideología integrada en la constitución china en 2017 y, por tanto, obligatoria.

En ALYC, el objetivo de la estrategia pacífica de China es no alterar y desafiar el orden regional establecido por el poder estadounidense. Por medio de una política exterior económica que tiene como objetivos el libre comercio, la inversión y el financiamiento, en el cual ofrece relaciones de ganar-ganar, ha establecido una red de nuevas relaciones estratégicas que podrían funcionar como un instrumento para la resolución de conflictos multilaterales y bilaterales. Algunos ejemplos son las disputas comerciales, la reunificación territorial con Taiwán y el apaciguamiento de los intentos de contención de China por parte de EE.UU.

A la par de la política económico-comercial, se agrega la ejecución de la política cultural activa en ALYc, la cual tiene tres ejes: las artes, la filosofía y el idioma chino. En la región se han establecido 40 institutos Confucio, en los que estudian más de 100.000 alumnos. Destacan los programas de intercambio académico y las becas para estudiar en las universidades de la nación asiática. Alrededor 
de 500 becados viajan cada año para profundizar sus estudios sobre la cultura china. El gobierno chino valora la cultura como una forma estratégica de insertarse en la era global, yendo más allá de sus relaciones económicas y políticas que dominan la mayor parte de su agenda global. La figura de Confucio se erige como un signo moral de las relaciones entre China y el mundo. Existe un fomento del nacionalismo interno como instrumento de cohesión social, además de proyectarse globalmente como una nación pacifista.

Actualmente, China no es percibida en la región como una amenaza militar, no cuenta con una red de bases militares ni representa el principal mercado de armas para ALYC, pese al armamento de bajo costo comparado con el estadounidense. De 2014 a 2018, EE.UU. siguió siendo el principal vendedor de armas en la región: ofrece garantías y alta tecnología. Con base en los datos de SIPRI 2019, su principal comprador en ALYC es México, que acapara el $72 \%$ de la compra respecto de la subregión centroamericana. En el caso de Brasil, China no aparece como uno de los principales distribuidores de armas, como sí lo hacen Francia, Estados Unidos y Reino Unido (Wezeman et al., 2019: 6, 8 y 9), pese a ser el país sudamericano uno de los socios estratégicos más importantes de China en el orbe regional.

En un escenario regional cambiante, China se enfrenta a nuevos factores de incertidumbre: al antiglobalismo y el neonacionalismo xenófobo y racista que se han reforzado cada vez más. El arribo de Donald Trump al poder en EE.UU.; el regreso de las derechas al poder en ALYC - Argentina, Chile, Colombia, Paraguay, Brasil, Guatemala, Honduras, El Salvador, entre otrosy de gobiernos de izquierda con objetivos totalitarios - Nicolás Maduro en Venezuela - y autoritarios -Daniel Ortega en Nicaragua-, ponen en un dilema a la política exterior china. A ello se suma el cambio de régimen en el otro polo de poder regional, con México, liderada por amLo, que se inclina a la izquierda progresista. Todos estos cambios generan un reacomodo político en la forma de relacionarse de ALYC con los grandes poderes como China, Rusia y EE.UU.

Sin duda, también los países de ALyc han buscado reacomodarse ante los nuevos cambios de la economía internacional. A nivel regional existe un mayor dinamismo para encontrar un consenso frente a los desafíos que representan los proteccionismos y las crisis económicas. Tal es el caso de la Alianza del Pacífico - Chile, Perú, Colombia y México - fundada en 2011 y el Tratado Integral y Progresista de Asociación Transpacífico (CPTPP, por su sigla en inglés, también conocido como TPP-11), en un primer momento liderado por Estados Unidos, firmado por México, Chile y Perú el 8 de marzo de 2018. ${ }^{5}$ Este último fue un intento

5 Los demás países signatarios son Australia, Brunei, Canadá, Malasia, Japón, Nueva Zelanda, Singapur y Vietnam. 
de contener el avance chino en el área del Pacífico asiático y latinoamericano.

Para China, la pregunta principal es: ¿̨cómo actuar en las crisis políticas y económicas, sin intervenir en los asuntos internos de los Estados, sin que ello signifique la falta de responsabilidad como un actor global? A pesar de los cambios en el espectro político -del arribo de gobiernos de corte progresista al ascenso de gobiernos conservadores- y del surgimiento de nuevas plataformas de integración regional en ALYC, China ha puesto en marcha una política exterior que responde con pragmatismo y cautela hacia las ideologías heterogéneas, porque trata de no inmiscuirse en posibles conflictos con otros Estados y, de manera simultánea, es defensiva porque se fundamenta en los principios de no agresión y no interferencia en los asuntos internos de los países, al relacionarse de manera bilateral. En suma, la actuación global china está en coexistencia con los principios de su política exterior.

\section{LA POLÍTICA EXTERIOR ECONÓMICA}

"Estamos comprometidos con el desarrollo del libre comercio y de la inversión a nivel global, y - por medio de la apertura - promover y facilitar la liberalización del mercado y las inversiones, y ser claros en la lucha contra el proteccionismo" (Xi, 2017). Estas palabras fueron parte del discurso del presidente de China, Xi Jinping, pronunciadas en el Foro Económico Mundial en Davos, Suiza, el 17 de enero de 2017. De acuerdo con esta política exterior de promoción del libre comercio, se realizó el I Foro de la Franja y la Ruta para la Cooperación Internacional, auspiciado por el gobierno chino y celebrado en Beijing (14-15 de mayo de 2017), donde el jefe de Estado chino dio un nuevo impulso y definición a la IFR: "Es una plataforma de cooperación abierta, inclusiva y de beneficio mutuo, que refuerza la interconectividad de Eurasia y, al mismo tiempo, se mantiene abierta para África, América Latina y otras regiones" (Qiu, 2017). En febrero de ese mismo año, el ministro chino de Relaciones Exteriores, Wang Yi, definió a la IFR como "el mayor producto público que China ha ofrecido a la comunidad internacional" (Wang, 2017).

En el discurso oficial se anuncia un rompimiento con la política exterior de Deng Xiaoping de "ser buenos en pasar desapercibidos y nunca reivindicar el liderazgo". Rompimiento que, paradójicamente, profundiza las reformas económicas iniciadas por el mismo Deng en diciembre de 1978. Hoy en día, China asume un papel protagónico en la agenda internacional -aunque reticente en temas como los derechos humanos y la democracia-, tiene un proyecto nacional unido al de una política exterior de largo plazo. Enfatiza su 
autonomía y autodeterminación nacional, pero profundiza su inserción en el mundo. Un mayor protagonismo conlleva grandes desafíos y áreas de oportunidades.

El presidente Xi Jinping se ha encargado de profundizar la reforma económica de 1978, donde el Estado chino produce y posee el capital de los activos industriales y financieros, concentra los ingresos fiscales y los gastos del gobierno. Al mismo tiempo, se expande globalmente mediante una política exterior activa y asertiva, lo cual lo hace inseparable del desarrollo del capitalismo global, sin perder la reflexión crítica no solo para describir el mundo desigual y antidemocrático, sino para actuar con fuerza dentro de él y así transformarlo a su semejanza. China hace de la praxis marxista y la idea de transformar al mundo de la filosofía china un instrumento útil.

En el cuadro 1 se presenta la evolución de las declarativas de las asociaciones y los tratados comerciales desde la década de 1990 hasta 2018. En él se observa que a partir de la asunción de Xi Jinping al poder, su política exterior activa en ALYc se ha limitado -o la han limitado- a establecer diversas asociaciones estratégicas, sin firmar ningún Tratado de Libre Comercio (TLC). Esto puede ser por la percepción de daño que pueda ocasionar en los sectores económicos más sensibles de las naciones latinoamericanas. Asimismo, otro problema que obstaculiza el incremento de TLCS con ALYC, junto con las inversiones en los sectores energético y minero, es la percepción nacionalista que se tiene sobre las materias primas y los recursos naturales. En varios países de la región son aún renuentes en la explotación, provisión y control extranjero de tales recursos, por ser considerados como símbolos de soberanía. Aun cuando por parte de China está el interés por cambiar el modelo económico-comercial en su relación con ALYc, la región tiende a ser proveedora de recursos primarios estratégicos para el logro de sus metas económicas. 
Cuadro 1.- Declarativas de asociaciones y tratados comerciales suscritos por China en América Latina, 1993-2018

\begin{tabular}{l|l|l} 
Asociación/Tratado & País & Firma \\
Asociación Estratégica & Brasil & 1993 \\
Asociación de Cooperación Integral & México & 1997 \\
Asociación Estratégica & Venezuela & 2001 \\
Asociación Estratégica & México & 2003 \\
Asociación Estratégica & Argentina & 2004 \\
Asociación de Cooperación Integral & Chile & 2004 \\
Asociación de Cooperación Integral & Perú & 2005 \\
TLC & Chile & 2005 \\
TLC & Perú & 2009 \\
TLC & Costa Rica & 2010 \\
Asociación Estratégica Global & Brasil & 2012 \\
Asociación Estratégica & Chile & 2012 \\
Asociación de Cooperación Integral & Trinidad y Tobago & 2013 \\
Asociación Estratégica Integral & Perú & 2013 \\
Asociación Estratégica Integral & México & 2013 \\
Asociación Estratégica Integral & Argentina & 2014 \\
Asociación Estratégica Integral & Venezuela & 2014 \\
Asociación Estratégica & Costa Rica & 2015 \\
Asociación Estratégica Integral & Chile & 2016 \\
Asociación Estratégica & Uruguay & 2016 \\
Asociación Estratégica Integral & Ecuador & 2016 \\
Asociación Estratégica & Bolivia & 2018 \\
\hline
\end{tabular}

Fuente: Elaboración propia.

Por su parte, Hu Jintao negoció y acordó tres TLCS, lo cual representa una hazaña políticamente histórica por la geopolítica regional. De cualquier manera, sin tener TLCs de por medio, los Estados se pueden apoyar mutuamente $\mathrm{y}$, aún más, profundizar sus interdependencias económicas, surgiendo con ello un nuevo paradigma en las relaciones económico-comerciales internacionales. Sin embargo, en términos del RP, los acuerdos internacionales podrían no cumplirse, ser violados o destruidos por los grandes 
poderes, y afectar a los poderes medianos y pequeños. Ello muchas veces limita el margen de maniobra de los Estados con menor poder.

En este artículo se identifican tres etapas de cambio de la presencia económica de China en ALYC y sus repercusiones en la política exterior. El primer período de cambio de la política de China en Alyc se distingue por la intensificación comercial desde la década de 1990, pasando por el ingreso de Beijing a la Organización Mundial del Comercio (oмc) en 2001 y finaliza en 2007, un año antes de la crisis financiera y económica global. Esta etapa se caracteriza por la creciente demanda de China de materias primas y recursos naturales estratégicos para sus planes económicos, y por la fuerte presencia de productos manufacturados chinos en los mercados latinoamericanos con un valor más bajo que los productos regionales.

Según la Comisión Económica para América Latina y el Caribe (CEPAL), entre 2001 y 2010, las exportaciones latinoamericanas de combustibles fósiles y productos mineros a China crecieron anualmente un 16\% y, al unísono, los productos agrícolas aumentaron un 12\% (OCDE, 2015: 17).

En esta primera etapa, China declaró las asociaciones estratégicas con Venezuela (2001), México (2003, año en que Beijing se convirtió en su segundo socio comercial) y Argentina (2004), y las asociaciones de cooperación integral con Chile (2004) y Perú (2005). Cabe señalar que Brasil fue el primer país latinoamericano en declarar una asociación estratégica con el gobierno de Beijing en 1993 y Chile también fue la primera nación de ALYC en suscribir un TLC con China en 2005.

Como lo muestra el Gráfico 1, a partir de la integración de China a la omc, los flujos comerciales con los países de ALYC han tenido un extraordinario incremento, incluso sustituyendo a EE.UU. como primer socio y mercado principal. Entre 2000 y 2013, el comercio sino-latinoamericano se multiplicó 22 veces. En 2017, el comercio de bienes alcanzó los 266.000 millones de dólares, lo que significó un avance del 53\% (CEPAL, 2018a). En ese mismo año, China fue el destino del 10\% de las exportaciones de bienes de ALYC al mundo y el origen del $18 \%$ de sus importaciones (CEPAL, 2018b: 39). Para 2018, según la Administración General de Aduanas (Aga) de China, Beijing continúa siendo el segundo socio comercial de ALYC y el volumen del comercio bilateral alcanzó un record de más de 307.400 millones de dólares en 2018 (Xinhua, 2019a). 
Gráfico 1.- América Latina y el Caribe: comercio de bienes con China, 2000-2018 (en miles de millones de dólares)

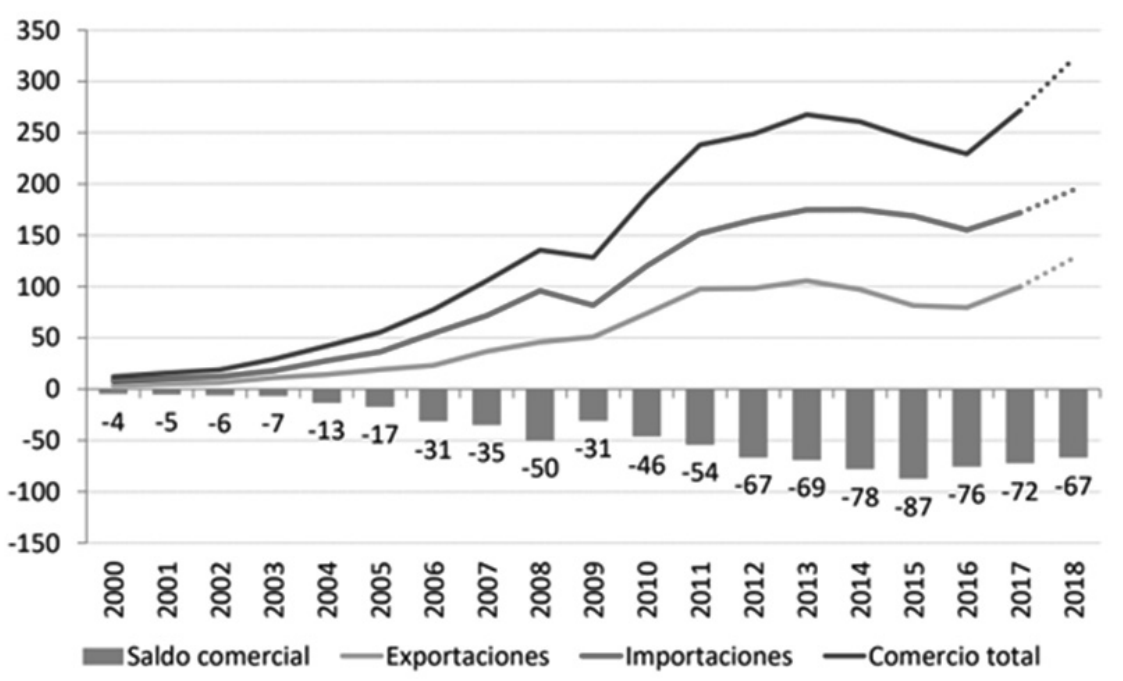

Fuente: CEPAL, con información de la Base de Datos Estadísticos de las Naciones Unidas sobre el Comercio de Productos Básicos (сомтRAde, por sus siglas en inglés). Las cifras para 2018 son proyecciones.

El segundo cambio del comportamiento económico chino en ALYC se inicia en 2008 y finaliza en 2012. Este corresponde a la llegada creciente de la inversión extranjera directa (IED) y de los préstamos chinos, así como al constante aumento de exportaciones de materias primas y recursos naturales latinoamericanos. De esta manera, China emerge como un Estado inversor potencial en la región. En 1990, la IED de China fue de 7.000 millones de dólares y, en 2010, se aproximó a los 14.000 millones de dólares, equivalentes al $11 \%$ de la IED total recibida en la región. De esta inversión china, las petroleras estatales, Sinopec en Brasil y China National Offshore
Oil Corporation (CNOOC) en Argentina (CEPAL, 2015a: 61), adquirieron capitales de forma parcial o fusión con otras compañías para desarrollar proyectos de exploración y producción de petróleo y gas.

Entre 2005 y 2016, el monto total de esa inversión se ha aproximado a los 90.000 millones de dólares. La IED procedente de China en la región tuvo un fuerte incremento en 2017, en más de 25.000 millones de dólares. Desde 2005 hasta 2017, Brasil ha sido el primer receptor de la Ied china (55\%), Perú el segundo (17\%) y Argentina el tercero (9\%). Se estima que China representa el 5\% de la IED recibida en ALYC (CEPAL, 2018b: 56). 
Con la crisis financiera y económica global en 2008, China se convirtió en el primer socio comercial de Brasil (2009), Chile (2010) y Perú (2010), y segundo de Argentina (2008) y Venezuela (2011). Sin tener TLCs con la mayoría de los países latinoamericanos, únicamente con Chile (2005), Perú (2009) y Costa Rica (2010), la influencia económica china aumentó en la región, pero los desajustes comerciales no tardaron en aparecer.

Desde 2012, la economía china se ha ido desacelerando, el producto interno bruto (РIB) en 2019 tuvo una caída real y prevista de $6,1 \%$ comparado con el alto crecimiento de 9,6\% en 2008 . Ante esta situación, el gobierno chino ha optado por modificar el modelo económico: impulsa el consumo interno y el sector servicios, aumenta el salario mínimo, apuesta por la mano de obra calificada, y da un peso secundario a la exportación, la industria y la inversión. Paralelamente a la disminución del crecimiento económico chino, ALYC ha registrado un crecimiento económico paupérrimo que, de acuerdo a cifras de la CEPAL, sería del $0,1 \%$ (EFE, 2019).

El boom de las exportaciones de las materias primas y los recursos naturales como el petróleo, el cobre, el carbón y el hierro, fue un aspecto favorable para los países exportadores latinoamericanos, pero la caída de sus precios - el volumen de exportación hacia China se ha mantenido (CEPAL, 2015a: 15- evidenció la ausencia de diversificación comercial y la precariedad de sus economías, Estados latinoamericanos sustantivamente débiles.

Es necesario recalcar que EE.UU. sigue siendo el principal socio comercial de ALYc. La venta de productos latinoamericanos es cinco veces mayor a las de China y la compra de bienes estadounidenses es casi el doble a la de su competidor asiático (EFE, 2018). La competencia por el mercado estadounidense y el desbalance comercial es negativa para los países manufactureros y textileros de aLYC, en especial para México y el Triángulo Norte de Centroamérica ${ }^{6}$, lo que ha provocado una actitud refractaria de los sectores económicos e incluso de los políticos hacia China. Contrariamente, los países sudamericanos exportadores de materias primas como la soja, el cobre y el petróleo, tenían un saldo positivo en su comercio con Beijing. En consecuencia, el tema económico-comercial se convirtió en el eje central de las agendas de las políticas exteriores de China y ALYc.

La relación económico-comercial entre China y ALYc, que evidencia la vinculación histórica entre

6 Dado que Guatemala y Honduras reconocen oficialmente a Taiwán, esto no ha sido obstáculo para mantener transacciones comerciales y que existan proyectos de inversiones en infraestructura con China. En Honduras, por ejemplo, la empresa estatal china Sinohydro participó en la construcción de la hidroeléctrica Patuca III, con un costo aproximado de 350 millones de dólares. 
centro-periferia, pero ahora entre dos economías en desarrollo, es ejemplo de las nuevas relaciones de intercambio y explotación, ya no únicamente entre un centro desarrollado y una periferia subdesarrollada. Dicho de otro modo, la dominación de la metrópolis y la subordinación de la periferia. A manera de ejemplo, de 2010 a 2015, las materias primas y los recursos mineros constituyeron la mayor parte de la inversión china en ALYC: tres cuartas partes de las fusiones y adquisiciones chinas estuvieron en las industrias extractivas - petróleo, gas natural y minería- En proyectos nuevos de inversión china en la región destaca el sector agrícola — greenfield - con un $18 \%$ comparado con la poca inversión en nuevas instalaciones con solo $2 \%$ (Ray et al., 2016).

En la tercera sesión plenaria del XVIII Comité Central del PCC, en 2013, Xi Jinping expuso una serie de pasos para perfeccionar y desarrollar "el sistema socialista con peculiaridades chinas": permitir que las fuerzas del mercado fueran el factor decisivo en la asignación de recursos, promover un sector privado fuerte y reafirmar la primacía del Estado sobre la economía. En este sentido, China se ha ido adaptando a las fuerzas de la globalización y adoptando ciertas medidas de apertura económica: transita a un modelo comercial-tecnológico sofisticado como la venta de software y celulares inteligentes, y busca espacios para la inversión en infraestructura y socios estratégicos para otorgar préstamos financieros.
El objetivo de la visita a ALYC de Li Keqiang en 2015 fue cambiar el modelo económico de China; de importador de materias primas y recursos naturales, y exportador de manufacturas a inversor en obras de infraestructura y exportador de productos de alta tecnología. En cambio, ALYC se convierte en un exportador de manufacturas y bienes de consumo duraderos a Beijing. En esta línea, el viceministro chino de Comercio, Tong Daichi, expresó que su país "está comprometido en diversificar el comercio con los países latinoamericanos y a importar productos de mayor valor añadido" (Vidal, 2015). Discurso que se ratificaría con la tercera visita de Xi Jinping a ALYC en 2016 y que se reflejaría en los acuerdos celebrados con sus homólogos de la región.

Ya en el contexto de la lucha comercial de Estados Unidos contra China, el denominado superciclo de las materias primas ha resurgido. El cambio de modelo económico propuesto por $\mathrm{Li}$ no ha cambiado, se ha reforzado y profundizado más. En 2017, los principales productos exportados al territorio chino son: porotos de soja, mineral de hierro, mineral de cobre, cobre refinado y petróleo. Los cuales representan el $70 \%$ del valor total de los envíos. En 2018, registrarían un alza de un 28\%. Aunque 2013 fue el año en que más dinamismo tuvo el comercio bilateral, en 2018 y 2019 alcanzaría un incremento sustancial, destacando la relación comercial entre China y Brasil.

$\mathrm{Si}$ bien los principales socios beneficiados con la disputa entre las 
potencias hegemónicas han sido los países de América del Sur, la especialización exportadora de productos primarios esconde la debilidad estructural de la relación entre China y ALYC, mostrando la falta de voluntad política de diversificar el modelo económico de la región. Así, la relación comercial se ha profundizado por la coyuntura sistémica, no por un plan económico estratégico e integral de largo plazo. Las nuevas formas del comercio globalizado tendiente a la sofisticación tecnológica y de servicios, vuelve más complejo el proceso de sinergia entre China y la región.

En la I Reunión Ministerial China-CELAC, el gigante asiático creó un fondo regional de 30.000 millones de dólares para la infraestructura y el desarrollo industrial en ALYc. En este sentido, la combinación de los créditos del Banco Mundial, del Banco Interamericano de Desarrollo y del Banco de Desarrollo de América Latina, han quedado disminuidos por los préstamos chinos en la región. En 2015, los créditos de China a ALYC se incrementaron a 29.100 millones de dólares (Sputnik,2016); en 2016 disminuyeron a 21.200 millones de dólares (EFE, 2017), y en 2017 hubo una notable reducción de esos préstamos a 9.000 millones de dólares, debido a la abstención de financiamiento de los bancos estatales chinos a Venezuela (Hernández, 2018).

Aún cuando ALYC en su conjunto no se ha endeudado con China, sí lo han hecho ya algunos Estados. Como puede observarse en el Cuadro 2, entre 2005 y 2018, los principales países receptores de los préstamos otorgados por el Banco de Desarrollo de China y el Banco de Exportaciones e Importaciones de China, han sido Venezuela, Brasil, Ecuador y Argentina. Sin embargo, el año más bajo en el financiamiento del Estado chino a ALYC fue en 2018, con un total de 7.700 millones de dólares en préstamos financiados por el Banco de Desarrollo de China y el Banco de Exportaciones e Importaciones de China. Desde 2005 hasta 2018, los bancos de propiedad estatal china han otorgado préstamos a ALYC por un monto total de 141.300 millones de dólares. 
Cuadro 2.- América Latina y el Caribe: principales países receptores de financiamiento de China, 2005-2018

\begin{tabular}{ll} 
País & $\begin{array}{l}\text { Monto } \\
\text { (millones de dólares) }\end{array}$ \\
\hline Venezuela & 67.2 \\
Brasil & 28.9 \\
Ecuador & 18.4 \\
Argentina & 16.9 \\
Trinidad y Tobago & 2.6 \\
Bolivia & 2.5 \\
Jamaica & 2.1 \\
México & 1.0 \\
Otros países & 1.3 \\
Total & $\mathbf{1 4 1 . 3}$ \\
\hline
\end{tabular}

Fuente: K. Gallagher y Margaret Myers, "China-Latin America Finance Database”, InterAmerican Dialogue, 2019.

En el marco de crisis políticas y económicas internas, China todavía no ha condicionado los préstamos en su totalidad. Estratégicamente, para Beijing el nuevo esquema de financiamiento le otorga acceso seguro a los yacimientos de hidrocarburos de los principales prestatarios latinoamericanos. No obstante, la desestabilidad en la región ha ido cobrando importancia para el no otorgamiento de los préstamos chinos. En el marco de la visita de Estado del Presidente venezolano Nicolás Maduro a China, en septiembre de 2018, según la consultora Ecoanalítica, el gobierno chino prestará a Venezuela 5.000 millones de dólares para proyectos petroleros y se firmó un memorándum de protección para las inversiones chinas. En cambio, el gobierno de Maduro debe crear un nuevo régimen cambiario y devaluar el bolívar venezolano (ввс, 2018). Sin que esto lo confirmaran las fuentes oficiales, esta es una situación desfavorable para Estados muy frágiles como el país sudamericano, pero relevantes para países poderosos como China, en especial por la adquisición de recursos naturales estratégicos como el petróleo.

Los grandes desafíos que enfrentarán los países de la región son las condiciones del financiamiento tanto directo, en recursos, como indirecto, en proyectos de infraestructura. Por ejemplo, de los países que están integrados a la IFR, Sri Lanka obtuvo un préstamo 
de China de 1.250 millones de dólares para la construcción del puerto de Hambantota en 2010 (eFE, 2017b), con una tasa de interés de $6,3 \%$, mientras que de los préstamos del Banco Mundial y el Banco Asiático de Desarrollo obtendría un interés de .25-3\% (Roy, 2017). A partir de la falta de pago, el gobierno esrilanqués, a cambio, ha permitido a la empresa China Merchant Port Holdings (СмРн) arrendar el 70\% de dicho puerto por un lapso de 99 años, con un monto de 1.100 millones de dólares (EFE, 2017b). En este caso, la deuda se capitalizó.

Así como el crecimiento de las inversiones en infraestructura y préstamos financieros en ALYC puede resultar un éxito para China, lo es también el problema del impago. Paradójicamente, este se podría convertir en un instrumento de condicionalidad para incrementar la influencia china sobre los gobiernos latinoamericanos, sin descartar las represalias políticas o sanciones económicas, como la transferencia de la deuda de los activos locales a propiedad china. Esta situación prospera por los obstáculos que los países de la región enfrentan para obtener el financiamiento de las instituciones financieras internacionales. Por consiguiente, la política del ascenso pacífico no sería tan amable.

Sería irónico que alyc trate de mantener una independencia financiera y política relativa de EE.UU., pero repite el patrón de dependencia de alto endeudamiento externo con China. Históricamente, el costo de la deuda externa ha sido alto y de largo plazo para la región. Como lo profetiza Carlos Marichal: "la crisis de la deuda externa que ha avasallado las economías de los países de Latinoamérica a fines del siglo xx no son las primeras ni serán las últimas de la historia moderna" (Marichal, 1999: 2). La devaluación de la moneda, la inflación y el alto endeudamiento estatal traerían una crisis económica con un impacto social profundo, repitiendo patrones que se creían superados.

En las dos décadas del siglo xxi estudiadas aquí, los temores de que China sea un poder agresivo han quedado disminuidos en los países donde los beneficios de la relación económica han sido tangibles: Brasil, Venezuela, Chile, Perú, Argentina, Ecuador y Costa Rica, entre otros. También China ha ido desplazando a la Unión Europea, Japón y Corea del Sur como socios económico-comerciales importantes en la región, ocupando espacios tecnológicos claves para las industrias de ALYC, por citar algunos ejemplos: la automotriz, la expansión de la comunicación inalámbrica $5 \mathrm{G}$, la aeroespacial y la construcción de represas hidroeléctricas. No obstante, ¿hasta qué punto la inversión económica de China en ALYc ha traído beneficios públicos? Punto que trataremos de responder más adelante.

A excepción de Cuba, la mayoría de los países de ALYC se han orientado hacia políticas económicas liberales. Independientemente del tipo de ideología política de los gobiernos de aLYc, el 
pragmatismo de las políticas exteriores utilizado por los Estados latinoamericanos les ha brindado la oportunidad de que China aumente los préstamos financieros, la inversión y el comercio con ellos. La convergencia de los modelos económicos liberales chinos y latinoamericanos ha hecho que sus lazos se profundicen aún más, en contraposición de las políticas proteccionistas implementadas por EE.UU., en particular, en la presidencia de Donald Trump. Para finalizar, la tercera etapa de cambio de China en ALYc la analizaremos en el contexto de la IFr.

\section{Desafíos sociales $y$ medioambientales}

Los principales desafíos que enfrenta la política exterior de China son los cuestionamientos sobre la falta de compromiso con los derechos humanos de las compañías chinas en ALYC, como efecto de su ascenso global. Para China, los derechos humanos no constituyen un objetivo de política exterior. Asimismo, no se ha hecho esperar su crítica a los países que la han juzgado y reprendido con medidas coercitivas ${ }^{7}$ por su no respeto a los derechos humanos al interior de su país. No obstante, a nivel externo, específicamente en ALYC, ella no se ha escapado de las presiones de las ongs regionales, sin que haya una apertura a las críticas exter-

7 Por ejemplo, el embargo de armas por las potencias occidentales en 1989, debido a la matanza ocurrida en la plaza de Tiananmen. nas y sin que exista una influencia real de estas organizaciones en la formulación de políticas de China que contribuyan a la mejora social, económica y ambiental de las comunidades locales.

Con todo, China ha ratificado algunos tratados internacionales en materia de derechos humanos y ha aceptado la legitimidad de las recomendaciones de algunos Estados sobre la materia. Pero hay un resquemor del gobierno chino al afrontar las violaciones manifiestas y las consecuencias graves al medio ambiente. Como muestra, el hecho de que China forme parte del Comité de Derechos Económicos, Sociales y Culturales (CDESC) en su Observación General No. 245, de los Principios de Maastricht sobre las Obligaciones Extraterritoriales de los Estados en el área de los Derechos Económicos, Sociales y Culturales, y del Pacto Internacional de Derechos Económicos, Sociales y Culturales (PIDESC), obliga a China a respetar los derechos humanos y, por ende, garantizar su protección. De los 26 convenios de la Organización Internacional del Trabajo (оIт) ratificados por China, 20 están en vigor, cinco han sido denunciados y uno ha sido abolido. De esos convenios activos, ocho se refieren a los derechos fundamentales de los trabajadores.

Por el momento, únicamente describiremos algunas de las demandas que han surgido en torno al impacto negativo de algunas empresas chinas en la región y que, al no tomar medidas reales, la problemática se ha 
hecho más compleja. En octubre de 2018, el informe del Colectivo sobre Financiamiento e Inversiones Chinas (CICDHA $)^{8}$, llamado "Tercer Ciclo de la Evaluación Periódica Universal de la RPC desde Sociedad Civil. Casos de Argentina, Bolivia, Brasil, Ecuador y Perú" ha puesto al descubierto, de forma detallada, en los cinco países sudamericanos la violación recurrente de los derechos humanos por parte de las empresas con capital chino.

El texto documenta la falta de cumplimiento del Estado chino de sus obligaciones extraterritoriales en materia de derechos humanos en 18 proyectos económicos manejados por 15 empresas chinas, respaldados financieramente por seis bancos chinos en los Estados donde se llevó a cabo la investigación: Banco de China, Banco de Desarrollo de China, Banco de Exportaciones e Importaciones de China, Banco Mercantil de China, Banco de Construcción de China y Banco Industrial y Comercial de China. De los 18 casos documentados, siete pertenecen a la industria minera, seis a

8 El cicDHA se integra por el grupo de trabajo regional integrado por el Centro de Derechos Económicos y Sociales, cDes (Ecuador), Cooperacción (Perú), el Centro de Documentación de Bolivia, CEDiB (Bolivia), Proteja Amazônia (Brasil) y la Fundación Ambiente y Recursos Naturales, FARN (Argentina). El objetivo del Colectivo es "promover la buena gobernanza ambiental y el respeto a los derechos humanos, en el marco de los proyectos chinos en el sector de infraestructura e industrias extractivas en América Latina" la industria petrolera y cinco al sector hídrico. Asimismo, 15 afectan a territorios indígenas, $11 \mathrm{a}$ áreas naturales protegidas, cinco son patrimonio natural y cultural reconocidos por la Organización de la Naciones Unidas para la Educación, la Ciencia y la Cultural (unesCo, por sus siglas en inglés) y 12 corresponden a la región amazónica ecuatoriana, boliviana y brasileña. De manera resumida, con base en el informe, narraremos la problemática que viven los pobladores locales y las consecuencias negativas que padece su entorno.

En Argentina, la construcción del proyecto hidroeléctrico Cóndor CliffBarrancosa no ha sido sometida a consultas directas con los pueblos indígenas, liderados por la comunidad Lof Fem Mapu. Por ello, las reacciones negativas de la población afectada han incidido para organizarse y clamar justicia. El 21 de diciembre de 2016, la Corte Suprema de Justicia de la Nación suspendió la construcción de las represas hasta que se realice un estudio detallado sobre la evaluación del impacto ambiental. Entre los daños ambientales más importantes destaca el que recaería sobre el Campo de Hielo Patagónico Sur, que alberga la tercera reserva de agua dulce del mundo. Del mismo modo, la construcción del complejo hidroeléctrico afectaría el patrimonio cultural y arqueológico de las comunidades indígenas Mapuche Tehuelche de Lof Fem Mapu, sus 
dinámicas asociativas y cosmovisión del mundo en torno al río.

En Bolivia, el área de exploración petrolera Nueva Esperanza está ubicada en territorio indígena Tacana, donde habita en aislamiento voluntario la comunidad indígena toromona. Frente a los graves daños ambientales de largo plazo que ha ocasionado la petrolera china BGP, finalmente el gobierno boliviano aceptó realizar el proyecto inconsulto con los pueblos originarios. Aún con estas condiciones, la empresa estatal Yacimientos Petrolíferos Bolivianos y/ BGP Bolivia han anunciado que continuarán con la explotación petrolera en el mismo territorio.

En Brasil, la empresa hidroeléctrica uHE São Manoel, al este del Amazonas, ha destruido los espacios culturales y sagrados que son parte de la cosmología de las comunidades indígenas munduruku, kayabi y apiaka. Por ejemplo, el daño al sitio "Morro de los Monos", descrito por los indígenas como lugar donde habitan los espíritus de los animales. Ahí, la calidad del agua se vería deteriorada y el río Teles Pires cambiaría su comportamiento hidrológico, de tal modo que la subsistencia de los pueblos originarios se vería altamente amenazada, porque la pesca y la caza de tracajás es parte de su alimentación principal. Por el momento, al no tener suministro de agua potable, la población de esta zona ha sufrido diarreas, vómito y otros problemas gastrointestinales debido a la acumulación de sedimentos y otros contaminantes en el río.

En Ecuador, los problemas se concentran en los proyectos mineros Mirador y San Carlos Panantza, ubicados en la Cordillera del Cóndor, rodeada por un ecosistema rico en biodiversidad y hogar de las comunidades indígenas kichwa y shuar. Aquí la crítica es hacia la exclusión que han sufrido las comunidades indígenas al no integrarlos en la toma de decisiones sobre el desarrollo de los proyectos: i) falta información detallada sobre los planes mineros; ii) no hay difusión de los Estudios de Impacto Ambientale (EIA) y iii) socialización discrecional. Asimismo, las empresas mineras chinas han recurrido a prácticas irregulares de adquisición inconsulta de tierras. Estas apropiaciones se han llevado a cabo con el apoyo de la fuerza pública, el desalojo forzoso y desplazamiento involuntario de un total de 42 familias indígenas.

En su primera fase de explotación, el proyecto Mirador ya ha generado graves impactos ambientales y ha alterado las formas de vida de comunidades, afectando su soberanía alimentaria, salud y medios de subsistencia. Por ejemplo, en marzo de 2018, el Ministerio de Ambiente suspendió temporalmente el 40\% del proyecto del Mirador por incumplimiento de la licencia ambiental y por realizar actividades sin los permisos respectivos. Otro fallo es por cuestiones de violación a los derechos laborales, ocurrido en 2009 , 
cuando la Corte Constitucional de Ecuador falló a favor de los trabajadores y sancionó a Andes Petroleum y PetroOriental.

En Perú, la empresa minera Shougang Hierro Perú SAA ha cometido más de diez infracciones ambientales, entre ellas, la violación de los límites de contaminación permitida en efluentes de agua y el incumplimiento de normas de manejo de residuos sólidos. No obstante, el Estado peruano ha sancionado las infracciones por incumplimiento de políticas administrativas y daño ambiental. Como consecuencia de la contaminación, ya se ha registrado alta presencia de metales pesados que superan los límites máximos permisibles; un mal manejo de las piscinas de relaves, que podría resultar en la ruptura del dique artesanal que amuralla tales piscinas; altísimos niveles de humedad que proviene del subsuelo y afecta las viviendas y la salud de los pobladores de Nueva Morococha. Cabe destacar que tan solo el 98,5\% de esa población ha sido reubicada para que el proyecto minero Toromocho opere sin dificultades.

Otro de los problemas que ha enfrentado la minera Shougang Hierro Perú es la huelga respaldada por la población de Marcona, en la provincia Nasca, realizada el 19 de mayo de 2015. Esto se debió al despido de más de 90 trabajadores por parte de la Cooperativa Coopsol, a quien la empresa china designó para contratar el personal.Los reclamos abanderaban la reposición de los trabajadores, el aumento del salario y la mejora de los servicios básicos que iban desde la calidad del agua potable y la reducción de tarifas de energía eléctrica, servicios que administra directamente la empresa china.

El 25 de mayo, producto del choque entre manifestantes y efectivos de la policía, falleció el ciudadano Luis Quispe Chumpi a causa de un disparo perpetrado, de acuerdo con los registros de la prensa, por un oficial, y junto a él, llegó Justo Elías Veliz Aguilar, quien fue herido de bala (El Comercio, 2015; Otra Mirada, 2015).

Por su parte, el 15 de marzo de 2019, el gobierno chino recibió 284 de 346 recomendaciones, que fueron sugeridas por algunos Estados en el marco de su tercer Examen Periódico Universal (epu), en el Consejo de Derechos Humanos de las Naciones Unidas (CDHNu) (China Daily, 2019). En la oportunidad, la delegación china señaló que su posición es "abierta y activa hacia la promoción y protección de los derechos humanos". De ALYC aceptó dos recomendaciones de las misiones diplomáticas de Ecuador y Perú (Cicdha, 2019).

En lo que se refiere a Ecuador, el gobierno chino se comprometió a "promover medidas que garanticen que los proyectos de desarrollo e infraestructuras dentro y fuera de su territorio sean plenamente compatibles con los derechos humanos y respetuosos con el medio ambiente y la sostenibilidad de los recursos naturales, de conformidad con el derecho nacional e internacional aplicable y con los 
compromisos de la Agenda 2030 para el Desarrollo Sostenible”. Respecto de Perú, va a "considerar la posibilidad de establecer un marco jurídico para garantizar que las actividades realizadas por las industrias sujetas a su jurisdicción no menoscaben los derechos humanos en el extranjero" (CICDHA, 2019).

$\mathrm{El}$ informe del cicDHa pone de manifiesto cinco características de las inversiones chinas en ALYC: 1) la falta de cumplimiento de los tratados internacionales firmados por China, que garanticen la protección y promoción de los derechos económicos, sociales, culturales y medioambientales de la población local; 2) la omisión y el silencio sobre las violaciones a los derechos humanos de los trabajadores hechas por las compañías chinas, acompañada de la corrupción, impunidad y falta de transparencia; 3) la ausencia de mecanismos de mediación y comunicación entre la población originaria y las empresas chinas, la cual evidencia la falta de apertura por parte del gobierno chino, sin la previa consulta a los pueblos originarios y comunidades indígenas; 4) entre mayor sea la inversión económica china, más notoria será la falta de normas legales que rijan las acciones de China en el extranjero y la tensión continua con su discurso oficial; 5) la ausencia del Estado de derecho y la debilidad de las instituciones latinoamericanas, generalmente caracterizadas por Estados frágiles.

La reacción de China ante las críticas de las ongs pareciera ser más de apertura restringida y no de total apertura como oficialmente se autodefine, pero será cuando nuevamente se lleve la revisión de las medidas implementadas que se podrá evaluar el compromiso, verdadero o falso, de China con la población local y el medio ambiente de ALYC.

En marzo de 2021, en la Revisión de Medio Término ante el CDHNu, el Estado chino deberá informar los avances realizados sobre la implementación de las recomendaciones hechas por las delegaciones de Ecuador y Perú. Para 2024, China tendrá que informar qué medidas ha adoptado para garantizar la protección de los derechos de las poblaciones locales y el cuidado del medio ambiente de esos Estados. Por su parte, las ongs de Argentina, Bolivia y Brasil, en materia de derechos humanos y medio ambiente, no han logrado que sus temas de interés se integren en la serie de recomendaciones hechas a China. Aunque las recomendaciones no son vinculantes, en realidad hay una obligación moral que China deberá cumplir.

\section{LA POLÍTICA MULTILATERAL}

El diálogo político entre China y ALYC se desarrolla en distintos foros multilaterales, como la Organización de las Naciones Unidas (ONU) y sus 
diferentes instancias, el Fondo Monetario Internacional, el Banco Mundial, el Banco de Pagos Internacionales, el Consejo de Estabilidad Financiera, el Comité de Supervisión Bancaria de Basilea, la омc, el Foro de Cooperación Económica Asia-Pacífico (APEC, por sus siglas en inglés), los BRICs (Brasil, Rusia, India, China y Sudáfrica), el G20 y en el diálogo ampliado de los líderes de los países industrializados que integran el G8 con sus contrapartes de Brasil, China, India, México y Sudáfrica (G5), la Organización de los Estados Americanos (OEA) donde China es aceptada como país observador permanente, el Foro de Cooperación América Latina-Asia del Este (FocALAE), la CELAC en el cual Beijing junto con el bloque regional latinoamericano buscan profundizar la cooperación integral y la concertación política y, recientemente, en la IFr. Cabe destacar que la Alianza del Pacífico ha manifestado la intención de integrar a China bajo el esquema de país asociado. La visión de China sobre la configuración de un orden global trae una nueva alternativa al diálogo multilateral para enfrentar los nuevos retos comunes.

Si bien el interés de China en la cooperación Sur-Sur viene poniéndose en práctica desde la década de 1980, es desde el establecimiento de la RPC que el gobierno chino se identificó como miembro del Tercer Mundo - Asia, África y América Latina-. Beijing ha continuado criticando el orden económico internacional excluyente $y$, con la finalidad de encarar el desarrollo económico desigual, ha ido fortaleciendo sus lazos con los países en desarrollo para superar los obstáculos comunes. En las primeras dos décadas del siglo xxi, China ha puesto especial énfasis en la reestructuración del orden económico y político internacional existente sobre la base de la igualdad, el beneficio mutuo y la cooperación de ganar-ganar para el desarrollo común, enfocándose en una diplomacia horizontal; es decir, hacia el Sur Global. La diplomacia multilateral regional le ha brindado a China la oportunidad de promover sus intereses y objetivos de política exterior, y acrecentar y mantener su presencia e influencia en ALYc, pese a que en muchas ocasiones sus intenciones se contrapongan a los de EE.UU.

En mayo de 2017, el texto publicado por el gobierno chino sobre la Construcción conjunta de la Franja y la Ruta: concepto, práctica y contribución de China hizo explícita la intención de que alyc participe en la IFR (China, 2017c: 66), lo cual muestra una fase más enérgica del interés de Beijing por la región. En efecto, con la llegada de $\mathrm{Xi}$ Jinping al poder en 2012, primero como secretario general del PCC y, en 2013, como Presidente y Jefe de Estado chino, la nación asiática ha implementado una nueva agenda y ejecutado una diplomacia activa en sus relaciones con la región. Sin embargo, en los primeros años del siglo xxı, la política exterior activa de China en la región no ha sido completamente nueva y exclusiva de Xi Jinping. Durante la 
presidencia de Hu Jintao se publicó por primera vez la posición y el interés del gobierno de Beijing por ALYC en el Documento sobre la Politica de China hacia América Latina y el Caribe en 2008, se declararon las asociaciones estratégicas con Venezuela, México y Argentina, y de cooperación integral con Chile y Perú, y se suscribieron tres TLCs con Chile, Perú y Costa Rica.

El primer Documento sobre la Politica de China hacia América Latina y el Caribe delineó las directrices de la relación de China con la región, dando prioridad a la cooperación económica y el fomento al desarrollo y, en el aspecto político, las relaciones diplomáticas se determinarían con base en la política de "una sola China"; esto es, el reconocimiento de que existe una sola China en la consistente política de aislamiento a Taiwán (China, 2008).

En 2016 hubo una nueva redefinición de las relaciones con la región, manifestado en un segundo Documento sobre la Política de China hacia América Latina y el Caribe. En este nuevo texto hay mayor preeminencia de la agenda económico-financiera, ratificada en la implementación de un nuevo programa de cooperación que se resumiría en la siguiente ecuación: $1+3+6$. El número 1 representa el Plan de Cooperación China-América Latina y el Caribe (2015-2019); el 3 se refiere a los ejes que marcan las prioridades del programa: comercio, inversión y cooperación financiera, y el 6 establece los sectores clave: energía y recursos, obras de infraestructura, agricultura, manufactura, innovación científica y técnica, y tecnologías de la información (China, 2016b). Esta propuesta quedó de manifiesto en el discurso del Presidente Xi Jinping, realizado en el marco de la I Reunión Ministerial China-CELAC, en enero de 2015, en Beijing. La II Reunión se efectuó en enero de 2018 en Santiago de Chile y la III Reunión se realizará en 2021, nuevamente en la capital china.

Así pues, China recurre a la política exterior como instrumento y continuación de la política interna para lograr el "Sueño Chino". Se busca "la gran revitalización de la nación china", que consiste en construir "una sociedad modestamente acomodada" para 2021, año en que se cumple el centenario del PCC, y para el 2049, año del centenario de la RPC, convertir a China en un Estado socialista moderno: "próspero, fuerte, democrático, avanzado culturalmente y armonioso", tal y como lo exclamó el primer ministro Li Keqiang, en la viri Reunión de Nuevos Líderes del Foro Económico Mundial, el 10 de septiembre de 2014, en Tianjin, China (énfasis añadido) (China, 2014a). Tres años más tarde, en el discurso que pronunció el presidente Xi Jinping durante el xix Congreso del PCC, reafirmó que en 2035 China se convertirá en "moderadamente próspera", no obstante, en 2050 ya sería "próspera, fuerte y democrática”.

La terminología moral utilizada por los gobiernos de $\mathrm{Hu}$ Jintao, pero más persistentemente en el de Xi Jinping, fomenta la cohesión interna $\mathrm{y}$ 
externa. La élite intelectual y política china subrayan la repercusión de la historia y la moral en la asunción y el ocaso de los gobiernos, es decir, lo que se debe y no se debe hacer para evitar la deslegitimización del PCC. Las directrices son: construir un nuevo nacionalismo de características chinas que se integre a la dinámica del capitalismo global y, paralelamente, criticar las ideas liberales como el individualismo y la ostentación. En efecto, el presidente Xi retoma los valores confucianos ${ }^{9}$ como guía moral y política en su lenguaje interno y externo, por ejemplo, en la actual política anticorrupción. Los términos de un "mundo armonioso", el establecimiento de relaciones internacionales con base en los principios de "beneficio mutuo", "ganar-ganar" e "igualdad", o el concepto estratégico de "el destino común para la humanidad y la paz y la estabilidad duradera", son los componentes principales de la retórica moral de China en la era de Xi Jinping, paralelo al resurgimiento del confucianismo.

Un ejemplo de ello es el discurso del mandatario chino en la I Reunión Ministerial China-CELAC: "China aboga por actuar con buena fe, valorar la amistad, hacer valer la justicia, y promover la moral, encontrándose en la disposición de vincular estrechamente nuestro desarrollo con el desarrollo de

9 Algunos de ellos son: ren 仁 (humanidad, autoejercicio, benevolencia o amor), $y i$ 義 (rectitud), $l i$ 禮 (rito), $z h i$ 知 (justicia) y $x i n$ 信 (fidelidad). los países en vías de desarrollo, con vistas a aunar esfuerzos por construir un nuevo tipo de relaciones internacionales, que tenga como núcleo la cooperación y la ganancia compartida" (CELAC). Discurso que contrasta con los de los grandes poderes. China matiza la preponderancia de los factores económicos y de seguridad en sus relaciones externas; toma los elementos morales como una forma estratégica de obtener aceptación en sus relaciones bilaterales y multilaterales.

En la II Reunión Ministerial China-CELAC se integraron nuevos temas en la agenda multilateral, como la cooperación en el combate contra las drogas, la corrupción y los delitos cibernéticos. Estos representan retos importantes tanto para ALYC como para China, por cuanto van íntimamente ligados a sus políticas internas. En el caso concreto de la corrupción, en 2012, en el xviII Congreso del PCC, cuando Xi Jinping tomó el poder, dio inicio a la política anticorrupción multinivel (provincial, central y, ahora, con un carácter internacional), que pondría en jaque a ciudadanos chinos que viajen a ALYC y estén siendo investigados por casos de corrupción. A partir de 2014 se ha implementado la política anticorrupción para capturar a los presuntos culpables que huyeron al extranjero con las operaciones internacionales llamadas "Red del Cielo" y "Caza del Zorro". En estas, hasta marzo de 2019, se había logrado detener a 5.000 fugitivos y recuperar más de 1.940 millones de dólares de activos robados (Xinhua, 
2019b), dando legitimidad y apoyo interno al gobierno de Xi Jinping.

No menos importante es mencionar la responsabilidad moral y legal del gobierno chino en la lucha contra las drogas. En mayo de 2019, el gobierno chino se comprometió a regular la producción del fentanilo y sus derivados debido a la petición de EE.UU., país con un alto índice de muertes causadas por el consumo de este opioide, siendo el principal mercado para su venta. Pese a las buenas intenciones, las mafias chinas siguen exportando variantes del fentanilo sin que se controle la producción en su interior.

En México, las autoridades estadounidenses y mexicanas han confirmado que los carteles más importantes como el de Sinaloa o Jalisco Nueva Generación (CJNG) han importado componentes para elaborar fentanilo y exportarlos al mercado estadounidense (Vicenteño, 2019). Y es que México es una plataforma estratégica para la llegada de drogas prohibidas debido a la corrupción sistémica y debilidad institucional. Desde la década de 1980, México ha representado una zona de tránsito para el tráfico de drogas originarias de Sudamérica hacia EE.UU., principal mercado de consumo de drogas. Desde fines de la primera década del siglo xxi hasta la actualidad, China ha aparecido como un actor casi determinante, de donde provienen las drogas de mayor consumo entre la población estadounidense: la metanfetamina, el fentanilo y los precursores químicos para su fabricación.
La situación geográfica de los carteles de Sinaloa y cJNG, que están ubicados en el área del Pacífico, facilita las comunicaciones para el tránsito de las sustancias prohibidas de origen chino. A modo de ejemplo, el registro de las principales incautaciones de fentanilo ha sido en lugares cercanos al océano Pacífico. El 18 de agosto de 2019, en el estado de Michoacán, la Fiscalía General de la República decomisó 34 toneladas y 46.000 litros de narcóticos y precursores químicos en laboratorios clandestinos para fabricar drogas sintéticas. El 26 de agosto del mismo año, en Lázaro Cárdenas, también en Michoacán, la Armada de México y la Unidad Naval de Protección Portuaria incautaron aproximadamente 23.368 $\mathrm{kgs}$. de fentanilo en un buque con bandera danesa que había llegado de China y se dirigía a Sinaloa (Infobae, 2019).

La aparición de China como origen de sustancias prohibidas no es completamente nueva. De igual forma, la pseudoefedrina importada de China es transformada en metanfetamina en México, y de allí se envía y distribuye en EE.UU., en el marco de un tráfico triangular. Zhenli Ye Gong, nacionalizado mexicano, pero de origen chino, fue acusado de comercializar ilícitamente en el Distrito Federal (hoy Ciudad de México) y Estado de México,al menos 54 toneladas de pseudoefedrina entre noviembre de 2004 y febrero de 2006, distribuyéndose tanto a empresas farmacéuticas transnacionales como a compañías privadas mexicanas (Fierro, 2015). 
Se tiene registro que el principal distribuidor de efedrina en México, José Paz Escandón, declaró ante la Procuraduría General de la República que Zhenli Ye Gon presuntamente sacaba dinero utilizando valijas diplomáticas de la embajada de China en territorio mexicano, mediante sus contactos de esa representación diplomática (El Universal, 2007). Por su parte, la embajada de China en México no se pronunció al respecto. Cualquier otra embajada habría exigido pruebas o de lo contrario hubiera amenazado con demandar a Paz por calumnias (Fierro, 2015).

Aunque ahora el contexto de China y México es distinto, hasta la fecha no se tiene un acuerdo vinculante $o$ política antidrogas en conjunto para combatir las amenazas del tráfico, no solo por el alto consumo que existe en EE.UU., sino también por el consumo en sus propios territorios, específicamente en el país latinoamericano y el resto de la región. Si bien es cierto que en el escenario multilateral China ha expresado un cierto interés por tratar el tema del combate a las drogas, los temas económico-comerciales preponderan en la agenda multilateral.

En ALYC, China se presenta como un "socio confiable", sin importar la ideología o sistema político del país con el que establezca relaciones, con el objeto de buscar el apoyo de las naciones latinoamericanas en los foros multilaterales — principalmente obtener votos en la $\mathrm{ONU}^{10}$ —, conseguir nuevos mercados para la exportación de sus productos, acceder a las materias primas y los recursos naturales, desarrollar nuevos espacios de acción para la construcción de infraestructura, ser un prestamista estratégico en la región y poner los temas de su interés en la agenda. Así pues, "China depende de una red mundial de lazos comerciales, así que por ningún motivo busca una confrontación directa con Estados Unidos. La prudencia, no la agresividad ni la asertividad y menos intervencionista, serán características de la política exterior de China" (Yan, 2019: 131).

Por medio de una diplomacia activa que conlleva visitas del Presidente al exterior $y$ encuentros con dirigentes de alto nivel, hasta 2019, Xi Jinping ha hecho cuatro viajes oficiales a ALYC y visitado 10 países de la región. La primera visita como jefe de Estado de Xi Jinping al continente americano (1-6 de junio de 2013) incluyó Trinidad y Tobago - ocasión que sirvió para reunirse con representantes de Antigua y Barbuda, Bahamas y Jamaica-Costa Rica, México y EE.UU., la segunda desde que él había asumido el poder en el PCC en noviembre de 2012. La primera fue a Rusia y Sudáfrica. En este marco, China ha buscado renovar, reforzar y relanzar — en el caso de México- sus relaciones con estos países por medio

10 Hasta febrero del 2020, China tiene relaciones formales con 24 países de los 33 que integran la región de ALYC. 
de acuerdos sobre inversión energética y en recursos minerales, cooperación en materia comercial, construcción e industria pesada (Reinoso, 2013).

Por segunda ocasión, Xi Jinping estuvo en ALYC entre el 15 y 23 de julio de 2014. Los países que visitó fueron Brasil, Argentina, Venezuela y Cuba. El principal objetivo de su estancia fue la promoción de la inversión en infraestructura china en la región, como el transporte ferroviario y la transmisión eléctrica de voltaje ultra alto (Vidal, 2015). Por tercera vez, entre el 17 y 23 de noviembre de 2016, el Presidente chino realizó una visita de Estado a Ecuador, Perú y Chile. Este viaje a ALYC se efectuó en el marco de la xxiv Cumbre de Líderes de la APEC celebrada en la ciudad peruana de Lima (China, 2016a).El viaje más reciente fue a Brasil, para asistir a la XI Cumbre de los BRICS, entre el 13 y 14 de noviembre de 2019. Cabe destacar que, Xi Jinping llegó a la región en medio de protestas políticas y sociales en Sudamérica (Venezuela, Argentina, Ecuador, Chile, Bolivia y Colombia). Aunque no tomó ninguna posición respecto de los conflictos sudamericanos, reafirmó que China "seguirá comprometid[a] con una política exterior independiente, orientada a la paz y al desarrollo pacífico".

De igual manera, las visitas de funcionarios chinos de alto nivel a América Latina han sido frecuentes. Del 18 al 26 mayo de 2015, el primer ministro chino, Li Keqiang, viajó a Brasil, Colombia, Perú y Chile. Destaca su estancia en Lima y Brasilia por la búsqueda de acuerdos sobre la construcción del tren bioceánico. Al término de la gira por esos cuatro países, en su discurso en la sede de la cepal en Santiago de Chile, Li afirmó que China_"cuenta con una capacidad de fabricación de equipos altamente rentable y tecnología integrada, mientras que América Latina [la] necesita para ampliar su infraestructura y modernizar su industria" (China, 2015).

En el plano histórico, para China la región latinoamericana ha tenido poca importancia geopolítica comparada con el Este de Asia o Asia Central. No obstante, en los últimos 11 años —hasta 2019—, el nombre de ALYc ha aparecido con mayor frecuencia en los discursos, declaraciones y proyectos de la política exterior china, adquiriendo un papel geopolítico cada vez más importante para sus planes globales.

En medio de las tensiones comerciales con EE.UU., China cuenta con una ALYC donde puede promocionar sus proyectos económicos y proyectarse como un actor global responsable, en el cual encontrará nuevos desafíos, pero también oportunidades. En los últimos años, China ha ampliado sus espacios de acción económica y política en Centroamérica y el Caribe. Como muestra, Panamá (12 de junio de 2017), República Dominicana (1 de mayo de 2018) y El Salvador (20 de agosto de 2018) rompieron lazos político-diplomáticos con Taiwán para dar su reconocimiento oficial a la RPC. En los últimos años, el gobierno de Beijing ha ido contrarrestando los logros 
diplomáticos de Taipei en Centroamérica - pivote tradicional de su política exterior ${ }^{11}$ -

Incluso la percepción de los países latinoamericanos hacia China ha mejorado, al menos antes de que la nueva epidemia del coronavirus surgiera en Wuhan, capital de la provincia de Hubei, a finales de diciembre de 2019. En el contexto del 70 aniversario de la fundación de la RPC en octubre de 2019, Pew Research Center llevó a cabo una encuesta para conocer la opinión internacional sobre China. El resultado muestra que en Brasil, México y Argentina - los únicos países de ALYC que aparecen-, en promedio, el 50\% de los encuestados tienen una opinión favorable de China: Brasil (51\% vs $27 \%$ ), México (50\% vs $22 \%$ ) y Argentina (47\% vs $24 \%)$ (Silver et al., 2019). La influencia de China como un nuevo poder extrarregional se ha manifestado en la población de estos países,

11 Hasta febrero de 2020, Taiwán tiene el reconocimiento como Estado soberano de nueve países en ALYc: Belice, Guatemala, Haití, Honduras, Nicaragua, Paraguay, San Cristóbal y Nieves, Santa Lucía y San Vicente y las Granadinas. La carencia de infraestructura en Centroamérica, así como su posición geoestratégica - cercanía a EE.UU. y el acceso a los océanos Pacífico y Atlántico- la convierte en un espacio de oportunidad para China en áreas clave: comercio, energía, infraestructura, transporte, telecomunicaciones y financiamiento. Es pertinente mencionar que Taiwán tiene oficinas de representación comercial en México, Colombia, Argentina, Brasil, Chile, Ecuador y Perú. ejerciendo ella un casi monopolio de sus actividades económico-comerciales internacionales, principalmente en Brasil y Argentina, sin menospreciar el peso determinante que tiene en la economía mexicana como segundo socio comercial desde 2003.

Cambio y continuidad diplomática: la Iniciativa de la Franja y la Ruta

La IFR es el proyecto de política exterior más importante de China desde su fundación en 1949. Probablemente sea el cambio más decisivo en su relación económica y político-diplomática con alyc. China - menciona Yan Xuetong - redoblará "esfuerzos para incursionar en los mercados extranjeros y mantener su acceso", por medio de la Ifr. "China busca conectar sus centros exportadores con mercados lejanos mediante una extensa red de rutas terrestres y marítimas" (Yan, 2019: 131).

Para que el mayor proyecto contemporáneo de China tenga éxito, ha abierto en un porcentaje más amplio su mercado interno a los productos extranjeros. Dos de las iniciativas de esa apertura relativa son: la instalación de la Feria de Importaciones de Shanghai y la reducción de aranceles a más de 850 productos a partir del 1 de enero de 2020, entre ellos se encuentran la carne de cerdo, aguacate, pescado, quesos y semillas, dando preferencia arancelaria a los productos de Chile, Perú y 
Costa Rica, en el marco de sus trcs bilaterales con China (Xinhua, 2020).

La IFR es continuación de la política económica lanzada en 1999 llamada Go out. Dicha política subraya la necesidad de que las empresas chinas, en su mayoría estatales, inviertan en el extranjero y diversifiquen sus fuentes de abastecimiento de materias primas y recursos naturales. En 2013, el Comité Central del PCC aprobó la reforma para la apertura de la economía china al mundo, especialmente a la apertura de las zonas interiores, costeras y fronterizas de China, mediante el desarrollo de nuevas rutas de transporte y la aceleración de las conexiones de infraestructura entre países vecinos y regiones. Estos cambios profundizan la reforma económica de 1978 y, en un primer momento, pusieron en marcha la diplomacia periférica, ahora esa diplomacia se ha expandido globalmente. En este proyecto, el PCC por medio del Estado sigue siendo el rector y promotor de la economía china.

El Banco Asiático de Inversión en Infraestructuras (BAII) tiene gran relevancia para la promoción del desarrollo entre los países miembros de la IFR por medio del financiamiento a los proyectos de infraestructura. Para Peter Cai, la migración de las fábricas chinas con exceso de capacidad a los países miembros de la IFR ayudaría a reducir el exceso de oferta en el país y contribuiría a construir las bases industriales de los países menos desarrollados (Cai, 2017: 13). En el caso de ALYC, hay cinco países que han solicitado su adherencia al BAII: en 2015, Brasil como miembro fundador potencial, aún es candidato a integrarse, y posteriormente, en 2017, Argentina, Perú, Venezuela, Chile, Bolivia y Ecuador son miembros prospectos.

En mayo de 2017, el i Foro de la Franja y la Ruta tuvo una amplia participación política de alto nivel: 29 jefes de Estado y gobierno, más de mil 500 delegados de 130 países y regiones, y 70 organizaciones internacionales. Incluso, el consejero de Estado chino, Yang Jiechi, la definió como "la mayor actividad diplomática multilateral propuesta y realizada por China desde la fundación de la RPC" (China, 2017b). De la región latinoamericana asistieron los presidentes de Chile, Michelle Bachelet, y Argentina, Mauricio Macri, y representantes de alto nivel de 20 países latinoamericanos (Qiu, 2017), que de alguna manera hicieron "visible" a ALyc. Probablemente, la escasa participación de los jefes de Estado latinoamericanos se debió al desinterés político y de precisión del proyecto para la región, incluyendo los objetivos y estrategias a seguir. El ir Foro de la Franja y la Ruta para la Cooperación Internacional se realizó en abril de 2019, redefiniendo su nombre.

Por el momento, no podemos evaluar si la IFr en ALYC será exitosa o no. Primero, porque en 2017 apenas se incluyó a ALYC en dicho proyecto. Segundo, porque aún no hay objetivos ni una estrategia clara de cómo se ejecutará en la región, aunque posiblemente los proyectos de infraestructura 
en diseño o en ejecución se anexen a la iniciativa. El primer proyecto oficial en ALYC vinculado a la IFR es la construcción del ferrocarril PanamáChiriquí, firmado en abril de 2018. ${ }^{12}$ Tercero, la institucionalización de la IFR es una condición necesaria para que en realidad la participación de ALYC sea efectiva. Pero por ahora no se ha hecho. Lo que se ha observado durante la segunda década del siglo xxI, es que China ha puesto en marcha una política exterior económica activa que promueve la inversión, tanto en préstamos financieros como en proyectos de infraestructura, obteniendo una fuerte presencia en la región, en especial, en Sudamérica y Centroamérica.

Actualmente, el desdén del Presidente Donald Trump por aLYc ha resultado favorable para la presencia e influencia de China en la región. El diálogo político entre los países latinoamericanos y Beijing ha aumentado - aunque no profundizado- en sus distintas plataformas multilaterales. Paralelamente, algunas naciones de la región también han empezado a diversificar sus lazos económicos, principalmente en sus esfuerzos a favor de la integración y la expansión en el mercado internacional, y la eliminación de las barreras arancelarias sobre productos industriales y agrícolas como el CPTPP.

Mientras no se desafíen los intereses de seguridad nacional de EE.UU. en ALYC, China podrá seguir erigiéndose como un actor importante en las políticas exteriores de los Estados latinoamericanos. En cambio, una política de contención contra China tendría un alto costo para los tres lados: China, EE.UU.y aLYc. Por ahora, el desafío de China será no imponer sus preferencias económicas sobre las morales, y que sus intereses se mantengan seguros en la región.

12 A inicios del 2020, se tiene registrado que los países latinoamericanos que se han suscrito a la IFR son: Antigua y Barbuda, Barbados, Bolivia, Chile, Costa Rica, Cuba, República Dominicana, Ecuador, El Salvador, Guyana, Trinidad y Tobago, Venezuela, Uruguay, Perú, entre otros, en total suman 19 Estados de la región que tienen convenios firmados con China para proyectos vinculados a esta iniciativa. La condicionalidad política —no reconocer a Taiwán como un Estado - y la condicionalidad económica de utilizar capital, material, mano de obra y servicios provenientes de China, son restricciones que varios de los Estados de la región han aceptado para ser parte de la IFR con la finalidad de promover las inversiones chinas en sus territorios para la construcción de infraestructura. 


\section{REFLEXIONES FINALES}

A lo largo de dos décadas, los nexos entre China y alyc se han profundizado con algunos matices. Por un lado, porque son los países sudamericanos, aun cuando han existido cambios político-ideológicos en sus gobiernos, los que han aprovechado para consolidar la presencia económica y cultural-educativa de China en la región, la distancia geográfica con EE.UU. y su vacío ha ayudado a que el acercamiento político continúe. Por otro lado, la vecindad geográfica y dependencia excesiva de algunos países de Centroamérica y México con la superpotencia actual ha limitado la profundidad de la relación política con China, mas no ha frenado la interdependencia económico-comercial. Así pues, la región queda atada a una doble dependencia asimétrica respecto de China y Estados Unidos.

Fuera de estas diferencias, las encuestas recientes sobre la influencia que se tiene de China en ALYc muestran que la opinión pública tiene una percepción favorable hacia Beijing debido a su poderío económico, sin que esto signifique que de fondo dejen de existir problemas reales y altamente preocupantes. Como puede apreciarse, China ha hecho poco para esquivar y detener los efectos negativos de sus compañías en el territorio latinoamericano. Desafortunadamente, las comunidades indígenas y pueblos locales son los que enfrentan la desigualdad y la contaminación medioambiental, aunado a los problemas de salud y crisis cultural que ello ocasiona.

A través de la historia contemporánea, ALYC se ha distinguido por la presencia de diferentes movimientos armados y un ambiente político-social complicado. En caso de que los gobiernos nacionales no resuelvan las demandas sociales de las comunidades afectadas, estas podrían volverse inviables en la agenda de la política exterior de China al cambiarse las prioridades. Sin duda esto conllevaría un desafío moral para Beijing. No obstante, aun cuando la política exterior de China se convierta en una más sensible, no resolverá los problemas estructurales que enfrentan los Estados latinoamericanos en su interior. Al menos, el gobierno chino puede intentar que su retórica moral sea congruente con sus acciones globales.

La respuesta del gobierno de $\mathrm{Xi}$ Jinping ha sido confusa. Primero, demuestra la poca flexibilidad de su propio régimen político de corte autoritario al momento de escuchar demandas externas, a pesar - según Yan Xuetong — de tener el suficiente poder económico, militar y cultural.En estas circunstancias, la ausencia de flexibilidad política podría significar una debilidad estructural de China frente a ciertos tipos de actores sociales, como las ongs.

Segundo, la política exterior moral de China la utiliza para posicionar ciertos temas en los foros multilaterales 
convenientes a sus objetivos e intereses nacionales, como la reforma de la onu o la promoción de la firma del Acuerdo de París. Al no girar la promoción de los derechos humanos y la democracia como parte de sus objetivos de política exterior, lo cual también es legítimo, el pragmatismo ha ayudado a no condicionar ideológicamente la relación, sin que esta sea cuestionada por los Estados latinoamericanos.

Tercero, en línea con el segundo punto, si bien a China no se le condiciona a salvaguardar y proteger los derechos humanos en el marco de sus proyectos económicos en ALYc, Beijing tiene firmados diversos convenios internacionales y regionales - no vinculantes- para su garantía. Por ejemplo, en la cláusula 2.2 de la Declaración de Santiago de la in Reunión Ministerial del Foro China-celac, se establece seguir colaborando conjuntamente para "la protección y promoción de los derechos humanos, el desarrollo sostenible, el crecimiento de nuestras economías, la reducción de la desigualdad y la erradicación de la pobreza”, y en el apartado 5.4. se comprometen a intensificar los derechos de "los pueblos indígenas y tribales, afrodescendientes y otros grupos vulnerables", entre otros más (China, 2018). Esto evidencia el desfase entre sus compromisos multilaterales con ALYC y su comportamiento real,y también lo complicado que es dialogar y consensuar intereses con la región.

Cuarto, la política exterior moral de China se encuentra en una tensión recurrente entre ser un actor más comprometido ante las demandas de las comunidades locales y no inmiscuirse en "asuntos internos" de otros países, o seguir siendo un actor extrarregional discrecional y guardar silencio frente a las violaciones a los derechos humanos que cometen sus empresas en ALYC.

De esta suerte, la tendencia de erigirse como líder moral queda expuesta cuando se cuestiona su autoridad, no de Estado a Estado, sino por la sociedad civil organizada. Es por esto que la política exterior moral de China hacia América Latina en el siglo xxı, en gran parte, deberá asumir sus compromisos internacionales - legalmente obligatorios-, así como mayores y efectivos convenios regionales vinculantes que coadyuven a la mejora de su percepción y posición en ALYC, como líder moral alternativo a los grandes poderes tradicionales y no quede tan solo en apariencia.

\section{Bibliografía}

BBC Mundo (2018). Maduro en China: la crucial relación de Venezuela con el gigante asiático. 13 de septiembre. Dispo- nible en https://www.bbc.com/mundo/ noticias-america-latina-45517326

Brown, C. (2001). "Ethics, Interests and Foreign Policy”, en E. Smith, K. y Light, M. 
(eds.), Ethics and Foreign Policy. Cambridge: Cambridge University Press.

Bulley, D. (2014). "Foreign Policy as Ethics: Toward a Re-Evaluation of Values”. Foreign Policy Analysis, Vol. 10, No. 2.

Cai, P. (2017). Understanding China's Belt and Road Initiative. Lowy Institute. Disponible en https://www. lowyinstitute.org/publications/ understanding-belt-and-road-initiative

Carr, E. (1939). The Twenty Years'Crisis: 19191939. Londres: Macmillan.

CEPAL (2018a). CEPAL destaca la relevancia y oportunidad de estrechar los vínculos entre China y América Latina y el Caribe. 22 de enero. Disponible en https:/www.cepal.org/es/comunicados/cepal-destaca-la-relevancia-oportunidad-estrechar-vinculos-china-america-latina-caribe

CEPAL (2018b). Explorando nuevos espacios de cooperación entre América Latina y el Caribe y China. Disponible en https://repositorio.cepal.org/bitstream/ handle/11362/43213/1/S1701250_es.pdf

CEPAL (2015a). América Latina y el Caribe y China: hacia una nueva era de cooperación económica. Disponible en http://repositorio.cepal.org/bitstream/ handle/11362/38196/S1500389_es.pdf

CEPAL (2015b). China apuesta por vínculo estratégico con América Latina y el Caribe. 25 de mayo. Disponible en http://www.cepal.org/es/comunicados/ china-apuesta-por-vinculo-estrategico-con-america-latina-y-el-caribe

Chen, Y. (2015). "El reciente resurgimiento del confucianismo popular en China continental: el redescubrimiento de los confucianistas clásicos, las academias y los ritos”. Estudios de Asia y África, Vol. 50, No. 1 .

China. Ministerio de Relaciones Exteriores (2008).Documento sobre la política de China hacia América Latina y el Caribe. Disponible en http://www.fmprc.gov. cn/esp/zxxx/t521035.shtml

China. Embajada de China en Chile (2013). Los presidentes de China y Chile sostuvieron encuentro bilateral. Disponible en http://cl.china-embassy.org/esp/ sbxw/t1085194.htm

China.ElConsejo deEstado (2014a).Premier Li's speech at Summer Davos opening ceremony. Disponible en http://english.gov.cn/premier/speeches/2014/09/22/ content_281474988575784.htm

China. Ministerio de Relaciones Exteriores (2015).Li Keqiang pronunció importante discurso en la CEPAL. Disponible en http://www.fmprc.gov.cn/esp/zxxx/ t1268515.shtml

China. Ministerio de Relaciones Exteriores (2016a). Xi Jinping sale de Beijing para visita de Estado a Ecuador, Perú y Chile. 16 de noviembre. Disponible en http://www.fmprc.gov.cn/esp/wjdt/ wjzc/t1416104.shtml

China. Ministerio de Relaciones Exteriores (2016b). Documento sobre la política de China hacia América Latina y el Caribe. Disponible en http://www.fmprc.gov. cn/esp/zxxx/t1418256.shtml

China. Embajada de China en Brasil (2017a). Iniciativa do Cinturão e Rota aproxima China e Brasil, diz funcionário brasileiro. 15 de mayo. Disponible en http://br.china-embassy.org/por/ szxw/t1461508.htm 
China. Embajada de China en México (2017b). Foro de Franja y Ruta marca un camino claro para la cooperación futura: consejero de Estado chino. Excélsior, 20 de mayo. Disponible en http://www.excelsior.com.mx/ opinion/opinion-del-experto-nacional/2017/05/20/1164610

China. Oficina del Grupo Dirigente de Fomento de la Construcción de la Franja y la Ruta (2017c). Construcción conjunta de la Franja y la Ruta: concepto, práctica y contribución de Chi$n a$. Disponible en https://www.yidaiyilu.gov.cn/wcm.files/upload/ CMSydylyw/201705/201705110546043. pdf

China (2018). Declaración de Santiago. II Reunión Ministerial del Foro CELAC-China. Disponible en http://www. itamaraty.gov.br/images/2ForoCelacChina/Declaracin-de-Santiago--II-Foro-CELAC-China-VF-22-01-2018.pdf

China Daily (2019). UN praises China's progress in human rights. 21 de marzo. Disponible en https://global.chinadaily.com.cn/a/201903/21/WS5c92d755a3104842260b1b1a.html

CICDHA (2019). China se compromete ante las Naciones Unidas a respetar los derechos humanos en sus inversiones en el exterior. 18 de marzo. Disponible en http://chinaambienteyderechos.lat/ china-se-compromete-ante-las-naciones-unidas-a-respetar-los-derechos-humanos-en-sus-inversiones-en-el-exterior/

CICDHA (2018). Tercer Ciclo de la Evaluación Periódica Universal de la RPC desde Sociedad Civil. Casos de Argentina, Bolivia,
Brasil, Ecuador y Perú. Disponible en http://chinaambienteyderechos.lat/ informe-regional/

Kertzer, J.D.; Powers, K.E.; Rathbun, B.C. \& Iyer, R. (2014). "Moral Support: How Moral Values Shape Foreign Policy Attitudes"[versión electronica]. The Journal of Politics, Vol. 0, No. 0. Disponible en https://dornsife.usc.edu/assets/sites/897/ docs/Moral_Support.pdf

EFE (2019). La Cepal reduce su proyección de crecimiento para Latinoamérica al 0,1\% para 2019. 11 de noviembre. Disponible en https://www.efe. com/efe/america/economia/la-cepal-reduce-su-proyeccion-de-crecimien to-para-latinoamericaal-0-1-2019/20000011-4108525

EFE (2018). China se consolida como segundo socio comercial de Latinoamérica. 30 de noviembre. Disponible en https://www.efe.com/efe/america/economia/china-se-consolida-como-segundo-socio-comercial-de-latinoamerica/20000011-3828901

EFE (2017a). Los créditos de China a Latinoamérica en 2016 fueron de $21.200 \mathrm{mi}$ llones de dólares. 23 de febrero. Disponible en https://www.efe.com/efe/america/ economia/los-creditos-de-china-a-latinoamerica-en-2016-fueron-21-200-millones-dolares/20000011-3188705

EFE (2017b). Sri Lanka vuelve a mirar a China, pero solo por necesidad económica. 29 de julio. Disponible en https://www.efe.com/efe/espana/economia/sri-lanka-vuelve-a-mirar-china-pero-solo-por-necesidad-economica/10003-3339343 
El Comercio (2015). Ica: un muerto en protestas de trabajadores de minera Shougang. 25 de mayo. Disponible en https://elcomercio.pe/peru/ica/ ica-muerto-protestas-trabajadores-minera-shougang-366335-noticia/?ref=ecr

El Universal (2007). Zhenli usó valijas diplomáticas: testigo. 21 de agosto. Disponible en www.eluniversal.com.mx/ nacion/153500.html

Fierro, T. (2015). La política exterior de China hacia México durante la presidencia de $\mathrm{Hu}$ Jintao, 2002-2012. México: El Colegio de México, Centro de Estudios de Asia y África. Tesis de maestría para la especialidad en China.

Gallagher K. y Myers, M. (2019). "China-Latin America Finance Database", Inter-American Dialogue. Disponible en https:/www.thedialogue.org/map_list/

Gaskarth,J. (2017). "Rising Powers, Responsibility, and International Society”. Ethics \& International Affairs, Vol. 31, No. 3. Gilpin, R. (1988).“The Theory of Hegemonic War". The Journal of Interdisciplinary History, Vol.18, No. 4.

H. Gelb, L. y A. Rosenthal, J. (2003). "The Rise of Ethics in Foreign Policy: Reaching a Values Consensus”. Foreign Affairs, Vol. 82, No. 3.

Hernández, M.C. (2018). Financiamiento estatal chino en Latinoamérica, en el nivel más bajo desde 2012. France 24, 20 de abril. Disponible en http://www. france24.com/es/20180418-china-financiamiento-america-latina-venezuela

Infobae (2019). Así es como el fentanilo, una droga sintética letal, conecta a China, México y EE.UU. 8 de septiembre. Disponible en https://www.infobae. com/america/mexico/2019/09/08/asi-escomo-el-fentanilo-una-droga-sinteticaletal-conecta-a-china-mexico-y-eeuu/ Marichal, C. (1999). "Los ciclos de la deuda externa en América Latina en el siglo XX: una historia recurrente", en Palacios, M. (coord.), Historia General de América Latina, siglo XX, Madrid: Ediciones UNESCO, vol. VIII.

Mearsheimer, J. (2014). "Can China Rise Peacefully?” [versión electrónica]. The National Interest. Disponible en https://nationalinterest.org/commentary/ can-china-rise-peacefully-10204

Morgenthau, H. (1963). Politics Among Nations: The Struggle of Power and Peace, $3^{\text {th }}$ ed. Nueva York: Alfred A. Knopf.

Morgenthau, H. (1948). Politics Among Nations: The Struggle of Power and Peace. Nueva York: Alfred A. Knopf.

Nicholson, M. (1998). “Realism and Utopianism Revisited'[versión electronica].Review of International Studies, Vol.25, No. 5. Disponible en http://sro.sussex.ac.uk/ $\mathrm{id} /$ eprint/38025/1/S0260210598000655a. pdf

Nye, J. (2019). "What Is a Moral Foreign Policy?” [versión electrónica]. Texas National Security Review, Vol. 3, No. 1. Disponible en https://tnsr.org/2019/11/ what-is-a-moral-foreign-policy/

OCDE/CEPAL/CAF (2015). Perspectivas económicas de América Latina 2016: hacia una nueva asociación con China. Disponible en http://repositorio.cepal.org/bitstream/handle/11362/39535/1/ S1501061_es.pdf

Otra Mirada (2015). La Shougang, los dueños de Marcona. 10 de junio. Disponible en http://www.otramirada.pe/ 
la-shougang-los-due\%C3\%B1os-de-marcona

Prensa Latina (2017). Foro de la Franja y la Ruta, proyecto del siglo: presidente chino.14 de mayo. Disponible en http:// www.prensa-latina.cu/index.php?o=r$\mathrm{n} \& \mathrm{id}=85559 \& \mathrm{SEO}=$ foro - de-la-fran ja-y-la-ruta-proyecto-del-siglo-presidente-chino

Qiu, X. (2017). La Franja y la Ruta, nueva oportunidad para la cooperación chino-latinoamericana. El Financiero, 22 de mayo. Disponible en http://www. elfinanciero.com.mx/opinion/la-franja-y-la-ruta-nueva-oportunidad-para-la-cooperacion-chino-latinoamericana.html

Ray, R.; Gallagher, K. y Sarmiento, R. (2016). Boletín Económico China-América Latina. Disponible en https:/www.bu.edu/pardeeschool/files/2016/04/Economic-Bulletin-2016-Spanish.Final_.pdf

Reinoso, J. (2013). Xi Jinping hace las Américas. El País, 31 de mayo. Disponible en https://internacional.elpais. com/internacional/2013/05/31/actualidad/1369990029_816461.html

Reuters (2018). Brasil desiste de proyecto de tren al Pacífico por los altos costos. 2 de febrero. Disponible en https:// lta.reuters.com/article/domesticNews/ idLTAKBN1FM1TI-OUSLD

Rosenau, J. (1987). "Introduction: New Directions and Recurrent Questions in the Comparative Study of Foreign Policy”, en Hermann, C.F., W. Kegley Jr, C. y Rosenau, J. (eds.), New Directions in the Study of Foreign Policy. Boston: Allen \& Unwin.
Silver, L.; Devlin, K. y Huang, C. (2019). People around the globe are divided in their opinions of China. Pew Research Center, 5 de diciembre. Disponible en https://www.pewresearch.org/ fact-tank/2019/12/05/people-around-theglobe-are-divided-in-their-opinions-ofchina/

Sputnik (2016). Duelo de titanes: el dragón y el águila por América Latina. 19 de noviembre. Disponible en https://mundo.sputniknews.com/ economia/201611191064970946-china-eeuu-mercado-latinoamericano-intereses/

Vicenteño, D. (2019). Mandan fentanilo en medicina pirata; la DEA acusa a cárteles mexicanos. Excelsior, 5 de noviembre. Disponible en https:// www.excelsior.com.mx/nacional/ mandan-fentanilo-en-medicina-pirata-la-dea-acusa-a-carteles-mexicanos/1345891

Vidal, M. (2015). Li Keqiang impulsa la inversión china en Latinoamérica. El País, 18 de mayo. Disponible en https://internacional.elpais.com/ internacional/2015/05/18/actualidad/1431945139 524491.html

Wang, Y. (2017). Jointly build the Belt and Road, and advance regional cooperation. Disponible en http://www.fmprc. gov.cn/mfa_eng/zxxx_662805/t1440217. shtml

Wezeman, P.D.; Fleurant, A.; Kuimova, A.; Nan, T.y Wezeman, S.T. (2019). Trends in International Arms Transfers, 2018. SIPRI, marzo. Disponible en https://www. sipri.org/sites/default/files/2019-03/ fs_1903_at_2018_0.pdf 
Xi, J. (17 de enero de 2017). Discurso en la ceremonia de apertura de la conferencia anual de 2017 del Foro Económico Global. Disponible en http:// www.politica-china.org/imxd/noticias/ doc/1491907057XiJinping-ForoGlobalEconomico-2017-espanol__1_.pdf

Xinhua en español (2020). China reduce arancel de importación sobre carne de cerdo congelada. 1 de enero. Disponible en http://spanish.xinhuanet.com/202001/01/c_138671196.htm

Xinhua en español (2019a). Volumen de comercio China-América Latina supera 300.000 millones de dólares en 2018. 1 de febrero. Disponible en http://spanish. xinhuanet.com/2019-02/01/c_137792833. htm

Xinhua en español (2019b). La lucha contra la corrupción de China va de victoria en victoria. 12 de marzo. Disponible en http://spanish.xinhuanet.com/201903/12/c_137888922.htm
Yan, X. (2019). "La era de la paz incómoda”. Foreign Affairs Latinoamérica, Vol. 19, No. 2.

Yuen, F.K. (1992). Analogies at War: Korea, Munich, Diem Bien Phu and the Vietnam Decisions of 1965. Princeton, NJ: Princeton University Press.

Yan,X. (2014). "From Keeping a Low Profile to Striving for Achievement" [versión electrónica]. The Chinese Journal of International Politics, Vol. 7, No. 2. Disponible en https://academic.oup.com/ cjip/article/7/2/153/438673

Yan,X. (2013). “La competición entre China y Estados Unidos por el liderazgo mundial" [versión electrónica]. Documentos CIDOB Asia, No. 28. Disponible en https:/www.cidob.org/publicaciones/ series_pasadas/documentos/asia/pensamiento_chino_y_relaciones_internacionales_dos_miradas

Yan, X. (2011). Ancient Chinese Thought, Modern Chinese Power. Princeton: Princeton University Press. 